\title{
Biochar for the removal of detected micropollutants in South African domestic wastewater: a case study from a demonstration-scale decentralised wastewater treatment system in eThekwini
}

\author{
Jana Späth', Preyan Arumugam², Richard H Lindberg' ${ }^{1}$, Ovokeroye A Abafe ${ }^{3}$, Stina Jansson', Jerker Fick' and Chris A Buckley ${ }^{2+}$ \\ 'Department of Chemistry, Umeå University, SE-901 87 Umeå, Sweden \\ ${ }^{2}$ Water, Sanitation and Hygiene Research and Development Centre, School of Engineering, University of KwaZulu-Natal, \\ Durban 4041, South Africa \\ ${ }^{3}$ Residue Laboratory, Agricultural Research Council - Onderstepoort Veterinary Research Campus, Onderstepoort, South Africa \\ ${ }^{+}$deceased
}

\begin{abstract}
The presence of micropollutants, such as pharmaceuticals and personal care products, in surface and ground water has escalated globally, leading to adverse effects on aquatic organisms in receiving waters. Untreated or inadequately treated wastewater is the main source of micropollutants entering the environment. In South Africa, the consumption of antibiotics and antiretroviral drugs is relatively higher than other nations; however, little data exists on the identification and remediation of micropollutants in domestic wastewater. In this study, a novel method to detect and measure 71 micropollutants using online solid phase extraction liquid chromatography coupled to tandem mass spectrometry was developed. To test the method in the South African context, grab samples of the influent and anaerobically treated effluent (AF effluent) from a demonstration-scale decentralised wastewater treatment system in eThekwini (Durban) were taken over 3 consecutive days at 2 time points. The presence of 24 micropollutants was detected in the raw wastewater, with analgesics/anti-inflammatory drugs, antiretrovirals, and antibiotics showing the highest concentrations and with the majority of compounds still present in the AF effluent. One antibiotic, ciprofloxacin, exceeded its predicted no-effect concentration in all influent and AF effluent samples. This suggests that the anaerobic treatment of the raw wastewater was not effective in removing micropollutants. Preliminary data from lab-scale adsorption experiments using biochar produced from a set of 4 feedstocks - olive residues, tomato residues, rice husks, and the African palm tree Raphia farinifera - showed average removal rates for 4 compounds of up to $62 \%$. The application of biochar is thus recommended as a secondary treatment step in decentralised wastewater treatment for the removal of micropollutants in South Africa.
\end{abstract}

\section{INTRODUCTION}

Inward migratory patterns from rural areas into the cities for better livelihoods and employment opportunities occurs at a much faster rate than anticipated in developing countries, especially South Africa. In eThekwini, KwaZulu-Natal, rapid urbanisation has resulted in the formation of densely populated informal settlements within the urban edge. These communities are largely lacking societal infrastructure, including sewerage systems, which leads to poor living conditions and environmental pollution. The eThekwini Water and Sanitation (EWS) unit has provided provisional services in the form of community ablution blocks with washing, toilet, and shower facilities. However, the wastewater generated is routed to the sewer, adding a burden to already over-capacity conventional wastewater treatment works (WWTWs) with ageing infrastructure. Furthermore, water security is challenged by prolonged periods of drought and wasteful expenditure of potable water in agriculture, waterborne sanitation, leaks, etc. Dry sanitation seems like the feasible option. However, user experience has revealed that it is not always acceptable or appropriate as dry toilets are often associated with blockages and thus uncleanliness and bad odours (Roma et al., 2013). To prevent housing development delays and ensure user satisfaction, EWS has opted for waterborne sanitation in dense social housing schemes within the urban edge.

Extending the sewer network, which is accompanied by high capital costs, is not practical. The decentralised approach to sanitation offers more affordable solutions. The technologies used in these systems usually do not require any electrical or chemical input, lowering operating costs. To determine the feasibility of this approach, EWS, with the aid of the Bremen Overseas Research and Development Association (BORDA: https://www.borda.org/), constructed a demonstration-scale decentralised wastewater treatment system (DEWATS) in Durban, South Africa. The DEWATS has been operational since 2010 with a design flow of $41.6 \mathrm{~m}^{3} / \mathrm{d}$. Wastewater is generated from 84 households, designed to serve individuals who are unable to qualify for state-subsidised housing or personal home loans (GCIS, 2017). Treatment is anaerobic, at which stage the effluent, which is relatively high in ammonium and phosphate ions but low in suspended solids and organic matter compared to the raw wastewater, can be reused in agriculture (Odindo et al., 2016). If local agriculture is not possible and the effluent needs to be discharged to the aquatic environment, the anaerobically treated wastewater undergoes further treatment for nitrogen, suspended solids and pathogen removal.

\section{CORRESPONDENCE}

Jerker Fick

EMAIL

jerker.fick@umu.se

\section{DATES}

Received: 15 October 2020

Accepted: 15 October 2021

\section{KEYWORDS}

liquid chromatography-mass spectrometry online solid phase extraction organic micropollutants pharmaceuticals antiretrovirals antibiotics biochar adsorption

\section{COPYRIGHT}

(c) The Author(s) Published under a Creative Commons Attribution 4.0 International Licence (CC BY 4.0) 
More recently, emerging contaminants from anthropogenic activities also require monitoring in WWTPs. Antibiotic consumption in South Africa is one of the highest worldwide (Van Boeckel et al., 2014), while almost 7.9 million people live with HIV, $18.1 \%$ of which reside in KwaZulu-Natal (Simbayi et al., 2019). More than $60 \%$ of HIV-infected individuals are on antiretroviral treatment (UNAIDS, 2021) suggesting a high probability of wastewater contamination with these pharmaceuticals.

DEWATS in eThekwini are aimed to fill the gap in urban sanitation and serve communities arising from previously disadvantaged backgrounds. Since the prevalence of HIV, for example, is higher than in more affluent groups (Simbayi et al., 2019), it is expected that these treatment systems may be the source of elevated levels of pharmaceuticals. There will, of course, also be other micropollutants (MPs) present, arising from the usage of personal care products, various household chemicals, as well as pesticides and herbicides. Despite being present in very low concentrations (some in $\mathrm{pg} / \mathrm{L}$ ), the harmful effects of MPs on aquatic life include feminization of fish, caused by endocrine disrupting compounds (EDCs), oxidative stress of freshwater mussels and behaviour alteration in fish exposed to anxiolytics (Brodin et al., 2013; Margot et al., 2015).

Although the number of served households in DEWATS are limited, the concentration of MPs in treated effluents can be high ( $\sum$ MPs $>150 \mathrm{ng} / \mathrm{L}$ ) and will vary in concentration according to the diurnal flow rate of each system (Gago-Ferrero et al., 2017). Therefore, it is essential to thoroughly assess the MP load and removal efficiency of individual systems and find addon treatment solutions to mitigate the load to receiving waters. Generally, MPs are removed in WWTWs by either adsorption to the organic (lipophilic) layer of primary sludge or biodegradation in the secondary treatment step (Luo et al., 2014). Removal of MPs in WWTWs will depend on their physico-chemical properties but also differences in operational conditions, seasonal effects, etc., and for several MPs the overall removal will be inadequate (Luo et al., 2014; Lindberg et al., 2014; Yang et al., 2017; K'oreje et al., 2020). Tertiary treatment with, e.g., ozone or activated carbon, will increase the reduction of the MP load but comes with high costs and energy requirements (Hollender et al., 2009; Reungoat et al., 2012). A more cost-efficient option gaining interest is the application of biochar. Biochar, traditionally used for soil remediation, is produced from biomass by carbonization and can function as an adsorption material for various types of pollutants (Mohan et al., 2014). However, very little research has been done on the use of biochar for the removal of MPs from wastewater (Kyzas et al., 2015; Thompson et al., 2016; Weidemann et al., 2018; Oyjang et al., 2020).

While efforts to minimize and control the risks associated with MPs in the aquatic environment have been implemented in Europe, limited data are available on the detection and occurrence of MPs in South African wastewater. Olujimi et al. (2012) studied the occurrence and removal of 11 phenols and 6 phthalate esters in conventional WWTP influent and effluents. In KwaZulu-Natal, various pharmaceuticals, including antibiotics and antipyretics, were found in the Msunduzi River and Umgeni River (Agunbiade and Moodley, 2014; Matongo et al., 2015a,b), while Wanda et al. (2017) identified 6 MPs, such as carbamazepine and bisphenol A, in drinking and wastewater samples from Gauteng, Mpumalanga and the North West Province. Abafe et al. (2018) and Faleye et al. (2019) studied the occurrence of antiretroviral drugs and antibiotics in wastewater treatment plants and receiving waterbodies in Durban. To date, no studies have been conducted on the detection of MPs, especially pharmaceuticals, in DEWATS in South Africa.

This study aimed to evaluate the occurrence of MPs in the demonstration-scale DEWATS in eThekwini using online solid phase extraction liquid chromatography coupled to tandem mass spectrometry (LC-MS/MS); determine the current removal rates of the identified compounds by the treatment process; and explore the potential for enhancing the removal efficiency with biochar. The investigated compounds included several antibiotics, antiretrovirals, analgesics/anti-Inflammatory drugs, hormonal contraceptives, and herbicides/pesticides.

\section{METHODS}

\section{Site and sampling methodology}

The Newlands Mashu decentralised wastewater treatment system (NM DEWATS) is situated in Newlands East, KwaZuluNatal ( $29^{\circ} 46^{\prime} 25.648^{\prime \prime}$ S, $30^{\circ} 58^{\prime} 28.329^{\prime \prime}$ E). Raw wastewater from the 84 households is diverted from the main trunk sewer, passing through a stormwater overflow before entering the system. Primary treatment is in a 2-chambered settler, a 3-trained anaerobic baffled reactor $(\mathrm{ABR})$ followed by a 2-chambered anaerobic filter $(\mathrm{AF})$ (Fig. 1). The anaerobically treated effluent (AF effluent) from Train 1 of the ABR undergoes further treatment in a hybrid subsurface flow constructed wetland (CW) system consisting of a vertical downflow CW (VFCW) and a horizontal flow CW (HFCW), while flow from Trains 2 and 3 are used for agricultural trials, on site.

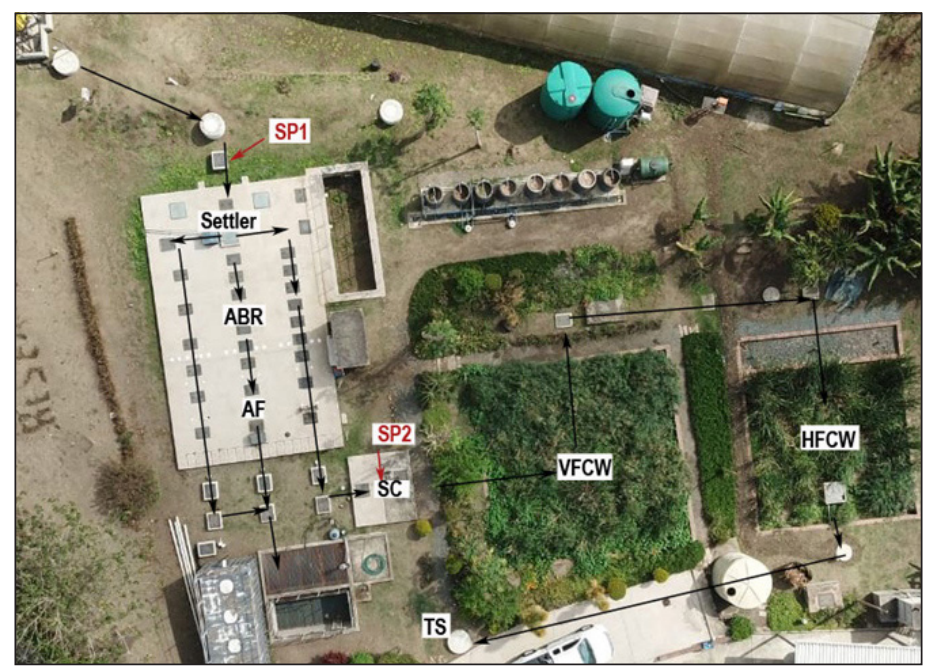

Figure 1. Aerial view of the Newlands Mashu decentralised wastewater treatment system (taken September 2019) $A B R=$ anaerobic baffled reactor; $\mathrm{AF}=$ anaerobic filter; HFCW = horizontal flow constructed wetland; $\mathrm{SC}=$ siphon chamber; $\mathrm{TS}=$ trunk sewer; VFCW = vertical flow constructed wetland. Black arrows denote the direction of flow. Flow from Train 1 of the ABR is further treated in a hybrid subsurface flow constructed wetland system. 
For this study, only the inlet and the AF effluent from Train 1 were sampled. Influent samples were taken directly at the inflow while the AF effluent samples were taken from the siphon chamber, which houses a mechanical dosing device (siphon) for the intermittent feeding of the VFCW. Composite samples at both sampling points were collected in $500 \mathrm{~mL}$ pre-rinsed PET bottles, as grab samples, over 3 consecutive days (29-31 March, 2016) at 2 time points (morning, 07:30-08:00 and evening, 18:00-18:30), and thereafter stored in the dark at $-20^{\circ} \mathrm{C}$ until analysis. Only one influent sample was taken on Day 2 (at 7:30). It is of course of great interest to also evaluate the performance of the wetland sections; however, due to the intermittent flux and the complexity of this part of the system, this aspect was omitted from this study. It should also be noted that not all DEWAT facilities are connected to a CW.

All samples were transported frozen to Umeå University, Sweden, for MP identification and quantification, chemical analysis and biochar production.

\section{Analytical methods}

Due to the lack of prescription data for pharmaceuticals in South Africa, the pharmaceuticals selected were based on the World Health Organisation (WHO) national list of essential medicines for South Africa (DOH, 2014). Compounds not compatible for LC-MS/MS analysis were excluded. Additionally, commonly used herbicides/pesticides in the region were selected. An analytical method was developed for a total of 72 selected analytes, divided into 18 different categories, including: antibiotics (12), analgesics/ anti-inflammatory drugs (9), antiretrovirals (8), psycholeptics/ antidepressants (7), antihistamines (4), anticonvulsants (4), antihypertensives (4), hormonal contraceptives (4), anticholinergics (3), herbicides/pesticides (2), antiarrhythmics (2), antidiabetics (2), antimycotics (2), antivirals (2), antidotes (1), antiparasitics (1), decongestants (1) and stimulants (1).

The methanol used for the standard solutions was of HPLC grade and purchased from Fisher Chemicals (Loughborough, UK). Hyper grade acetonitrile and methanol (LiChrosolv) for LC-MS were both purchased from Merck (Darmstadt, Germany). Formic acid (Fluka) as eluent additive was purchased from Sigma-Aldrich (Steinheim, Germany). Ultrapure Milli-Q water was produced from a Merck Millipore Advantage A10 system equipped with a Q-Pod unit. All standards and labelled standards were of analytical grade (above 95\%). Details of the CAS number, formula and supplier are given in Table A1 (Appendix).

Samples were thawed at room temperature and filtered through a $0.45 \mu \mathrm{m}$ Filtropur $S$ membrane filter (Sarstedt, Nürnberg, Germany). After filtration, $10 \mathrm{~mL}$ of each sample was spiked with $5 \mathrm{ng}$ of each internal standard and $10 \mu \mathrm{L}$ of formic acid (98\%).

On-line SPE was carried out by a Dionex UltiMate 3000 UHPLC system consisting of 2 LC pumps (Ultimate LPG 3400SD quaternary pump and HPG 3400RS binary UHPLC pump) with an Accela Open autosampler (Thermo Scientific), an on-line SPE column (Waters, Oasis HLB, $2.1 \times 20 \mathrm{~mm}, 15 \mu \mathrm{m}$ ), and an analytical column (Thermo Scientific Hypersil GOLD, 50 x $2.1 \mathrm{~mm}, 5 \mu \mathrm{m}$ ) equipped with a precolumn (Hypersil GOLD, $10 \times 2.1 \mathrm{~mm}, 3 \mu \mathrm{m}$ ). The column compartment was kept at $25^{\circ} \mathrm{C}$. Chromeleon Xpress (Thermo Scientific) was used to control the UHPLC system. Samples were injected onto a $1 \mathrm{~mL}$ loop and transferred to the online SPE column by quaternary pump using $0.1 \%$ formic acid in acetonitrile as eluent. After $60 \mathrm{~s}$, the autosampler valve switched and the binary pump started the elution from the on-line SPE column through the analytical column using a gradient of $0.1 \%$ formic acid in Milli-Q water and $0.1 \%$ formic acid in acetonitrile as mobile phase. Gradients for both pumps are shown in Table A2 (Appendix).
The UHPLC system was connected to a TSQ Quantiva triple quadrupole mass spectrometer (Thermo Scientific) equipped with a heated-electrospray ionization ion source operating in positive mode. The resolution for both quadrupoles was 0.7 FWHM. Spray voltage was $3500 \mathrm{~V}$, sheath gas 40 arbitrary units, sweep gas 0 arbitrary units, ion transfer tube temperature $350^{\circ} \mathrm{C}$, and vaporizer temperature $338^{\circ} \mathrm{C}$. For control of the mass spectrometer and data analysis, an Xcalibur (Thermo Scientific) was used.

Two MS/MS transitions - one for quantification, one for qualification - were monitored for all analytes. MS/MS transitions, corresponding collision energies and tube lens voltages, associated internal standards, and retention times for each analyte are shown in Table A3 (Appendix).

\section{Identification and quantification of micropollutants}

Compounds were identified based on retention time matching and the ratio of quantifier and qualifier ion. Internal standard calibration was used for quantification. Internal standards were assigned to the analytes according to the best match in terms of recovery: $10 \mathrm{~mL}$ of AF effluent and influent was spiked with $10 \mathrm{ng}$ of analytes and $5 \mathrm{ng}$ of internal standards and analysed in the same way as the samples. The internal standard that resulted in a recovery of a compound closest to $100 \%$ was selected (blank areas were subtracted). Assigned internal standards are shown in Table A3 (Appendix).

An 8-point standard curve was prepared in $10 \mathrm{~mL}$ Milli-Q water ranging from $20-10000 \mathrm{ng} / \mathrm{L}$. Calibration standards were prepared and analysed in the same way as the samples.

\section{Method validation}

The method was validated by spiking analytes into 3 matrices (Milli-Q water, AF effluent, and influent) and determining the following parameters: linearity, limit of quantification (LOQ), precision, accuracy, and filter recovery. Since several of the analytes were present in the AF effluent and influent, its areas in the non-spiked matrices were subtracted. Eight standard curve points (20-10 $000 \mathrm{ng} / \mathrm{L})$ were prepared in triplicate and analysed as described above. Linearity was expressed as $R^{2}$. LOQs were calculated using Eq. 1.

$$
\text { LOQ }=10 \times \frac{\text { STDEV }}{\text { slope }}
$$

where: STDEV is the standard deviation of the triplicates of the last visible standard curve point with $\mathrm{S} / \mathrm{N}$ above 10 .

To determine precision and accuracy, Milli-Q water, AF effluent, and influent were spiked with $10 \mathrm{ng}$ of analytes and $5 \mathrm{ng}$ of internal standards. Triplicates of each sample were prepared and analysed together with a calibration curve on 3 consecutive days. The concentration was determined by using the calibration curve analysed on the respective day. Intra-day precision was calculated as the ratio between standard deviation and average of the triplicates of the first day (x 100). Inter-day precision was calculated as the ratio between standard deviation and average of the triplicates on all 3 days ( $\mathrm{x}$ 100). Instrument precision was assessed by a triple injection of one sample on the first day. Accordingly, inter-day, intra-day, and instrument accuracy were determined by comparing average values with expected values.

Filter recovery was assessed by spiking AF effluent and influent before and after filtering through a $0.45 \mu \mathrm{m}$ Filtropur S membrane filter (Sarstedt, Nürnberg, Germany). 


\section{Removal efficiencies}

Removal efficiencies (REs) of the identified MPs in the decentralised wastewater treatment system were calculated according to Eq. 2:

$$
\mathrm{RE}_{\mathrm{i}}=\left[1-\left(C_{\text {eff }} / C_{\text {inf }}\right)\right] \times 100
$$

where: $\mathrm{RE}_{\mathrm{i}}$ is the removal efficiency for compound $i, C_{\text {eff }}$ the concentration in $\mathrm{AF}$ effluent, and $C_{\text {inf }}$ the concentration in influent.

When a compound was not detected in at least $60 \%$ of the influent and AF effluent samples, no RE was calculated.

\section{Biochar adsorption}

The biochars used were produced from a set of 4 feedstocks: olive residues, tomato residues, rice husks, and the African palm tree Raphia farinifera (RF), by torrefaction at $260^{\circ} \mathrm{C}$ for $3 \mathrm{~h}$ in a rotating furnace (Nordin et al., 2013). Torrefaction is a slow pyrolysis operated under mild conditions, at temperatures ranging between $200^{\circ} \mathrm{C}$ and $350^{\circ} \mathrm{C}$, ambient pressure, and with an inert atmosphere to avoid oxidation and combustion of the starting material (Nordin et al., 2013; Van der Stelt et al., 2011). Additional information about the biochar, including surface area, pore volume and surface characteristics, is given in Tables A4 and A5 (Appendix). Addition of biochar as remediation would most likely occur in the siphon, which is located after the ABR treatment. Wastewater influent and effluent (from the NM DEWATS in eThekwini) were therefore pooled in a ratio of 1:1, to take the variability of the concentrations of MPs into account and produce more robust results. $300 \mathrm{mg}$ of biochar was added to $30 \mathrm{~mL}$ of wastewater and each sample was shaken for $24 \mathrm{~h}$. Triplicates were prepared for each biochar, as well as biochar blanks (i.e. wastewater without char) $(n=4)$, and water blanks (Milli-Q water). After centrifugation, samples were filtered and analysed as described above.

\section{RESULTS AND DISCUSSION}

In all samples, MPs were successfully analysed with no carryover effects observed. $R^{2}$ values for all compounds were above 0.99 in Milli-Q water, AF effluent, and influent. Average LOQs were $21 \mathrm{ng} / \mathrm{L}$ (with a range of 2-200 ng/L) in Milli-Q water, $100 \mathrm{ng} / \mathrm{L}$ (with a range of $4-500 \mathrm{ng} / \mathrm{L}$ ) in the $\mathrm{AF}$ effluent, and $170 \mathrm{ng} / \mathrm{L}$ (with a range of 7-1 $000 \mathrm{ng} / \mathrm{L}$ ) in the influent, respectively. Inter-day, intra-day, and instrument precision for all matrices was below 20\% (maximum 18\%), and accuracy between 51 and $150 \%$. Filter recoveries in both AF effluent and influent were very low $(0-14 \%)$ for carvedilol, clotrimazole, etravirine, and saquinavir. Therefore, these compounds were excluded, and the filtration step retained to reduce the matrix effects and extend instrument performance. Average recoveries for the remaining 67 compounds were $90 \%$ and $110 \%$ for the $\mathrm{AF}$ effluent and influent, respectively. A summary of the method validation parameters is shown in Tables A6 and A7 (Appendix).

\section{Determination of MPs in the influent and AF effluent}

Micropollutants from 10 out of 18 compound classes targeted in this study were detected. In total, 24 MPs were present in at least one sample, of which 20 were present in all samples. The sum of all MPs detected was $287 \mu \mathrm{g} / \mathrm{L}$ and $179 \mu \mathrm{g} / \mathrm{L}$ in the influent and AF effluent, respectively, which correlates to a removal of $38 \%$. Average concentrations, based on 2 daily samples for 3 consecutive days, ranged from $25-140 \mu \mathrm{g} / \mathrm{L}$ in the influent and $22-130 \mu \mathrm{g} / \mathrm{L}$ in the treated AF effluent (Table 1). Twelve compounds were detected at elevated concentrations $(>1 \mu \mathrm{g} / \mathrm{L})$ in the influent and AF effluent. Paracetamol $(140 \mu \mathrm{g} / \mathrm{L})$, followed by the antiretroviral drug lamivudine $(74 \mu \mathrm{g} / \mathrm{L})$ and caffeine $(22 \mu \mathrm{g} / \mathrm{L})$, were the highest average concentrations in the influent, while in the $\mathrm{AF}$ effluent the antiretroviral drug darunavir $(10 \mu \mathrm{g} / \mathrm{L})$ and the antihypertensive enalapril $(8.1 \mu \mathrm{g} / \mathrm{L})$ were the highest, besides lamivudine $(130 \mu \mathrm{g} / \mathrm{L})$. None of the 7 psycholeptics targeted were found in any of the samples. Coefficients of variation (CVs) between sampling points were between 3 and 39\% in the AF effluent and 0-46\% in the influent, with the exception of abacavir and clindamycin which showed much higher CVs (100\% and $110 \%$, respectively). This variability in MP composition was likely to be caused by fluctuations in consumption, due to changes in number of people served each day (refer to Table A8, Appendix).

\section{Antibiotics}

Of the 12 antibiotics included in this study, 5 were found in all influent and AF effluent samples, with the lowest average concentrations for levofloxacin ( 25 and $22 \mathrm{ng} / \mathrm{L}$ in the influent and AF effluent, respectively) while the highest was sulfamethoxazole (12 and $2.5 \mu \mathrm{g} / \mathrm{L}$ in the influent and AF effluent, respectively). The presence of ciprofloxacin, clindamycin, and levofloxacin in South African wastewater has not been reported previously. Ciprofloxacin concentration was much higher than Swedish wastewater, where Lindberg et al. (2005) found concentrations up to 300 and $60 \mathrm{ng} / \mathrm{L}$ in the influent and effluent, respectively. Clindamycin and levofloxacin concentrations were similar to that detected in German wastewater (Rossmann et al., 2014). Compared to conventional South African WWTPs, Archer et al. (2017) detected sulfamethoxazole at lower concentrations of 2.6 and $1.6 \mu \mathrm{g} / \mathrm{L}$ in the influent and effluent, respectively, and trimethoprim at higher concentrations of 6.2 and $1.5 \mu \mathrm{g} / \mathrm{L}$, respectively). Antibiotics are known to promote antimicrobial resistance in exposed bacteria and therefore their presence in effluent poses a certain risk. BengtssonPalme and Larsson (2016) reported on predicted no-effect concentrations (PNEC) in terms of antibiotic resistance for 111 antibiotics. Comparing the PNEC with concentrations determined in this study, ciprofloxacin exceeds the PNEC of $64 \mathrm{ng} / \mathrm{L}$ in all influent and AF effluent samples, trimethoprim exceeds the PNEC of $500 \mathrm{ng} / \mathrm{L}$ in all influent samples and sulfamethoxazole the PNEC of $16 \mu \mathrm{g} / \mathrm{L}$ in one of the influent samples.

\section{Antiretrovirals}

Six of the eight targeted antiretrovirals were found in all influent and AF effluent samples, varying in average concentrations from a few hundred ng/L for abacavir and nevirapine up to several thousand ng/L for darunavir and lamivudine (Table 1). Concentrations of atazanavir, darunavir, and raltegravir were similar to concentrations measured previously at the NM DEWATS as well as at 2 conventional WWTPs in eThekwini (Abafe et al., 2018). Abacavir was found in German WWTP influent at similar concentrations while lamivudine and nevirapine were found at much lower concentrations than in South African wastewater (Prasse et al., 2010). Lamivudine and nevirapine were detected in both waste- and surface water in Kenya (K'Oreje et al., 2012; Wooding et al., 2017, K'Oreje et al., 2018, Muriuki et al., 2020), which implies that these antiretrovirals are semi-persistent.

\section{Other MPs}

The non-steroidal anti-inflammatory drug (NSAID), diclofenac, and the anticonvulsant, carbamazepine, are included in the European Commission's first watchlist. Bouissou-Schurtz et al. (2014) estimated PNECs for several pharmaceuticals according to the EU guideline. The average concentration of diclofenac in the AF effluent $(2.1 \mu \mathrm{g} / \mathrm{L})$ exceeds their proposed PNEC of $0.05 \mu \mathrm{g} / \mathrm{L}$ (for rainbow trout Oncorhynchus mykiss) and proposes a possible risk. The concentration of carbamazepine (280 ng/L) is below the PNEC of $2.5 \mu \mathrm{g} / \mathrm{L}$ (for zebrafish Danio rerio) (Bouissou-Schurtz et al., 2014). 
Table 1. Average concentrations (ng/L) of the identified micropollutants in influent and AF effluent samples of the Newlands Mashu decentralised wastewater treatment system, eThekwini, South Africa

\begin{tabular}{|c|c|c|c|c|c|c|}
\hline Compound & Influent $A V^{a}$ & $\mathrm{RSD}^{\mathrm{b}}$ & $n^{\mathrm{c}}$ & AF effluent $A V^{a}$ & $\mathrm{RSD}^{\mathrm{b}}$ & $n^{c}$ \\
\hline \multicolumn{7}{|c|}{ Analgesics/anti-inflammatory drugs } \\
\hline Diclofenac & 2300 & 13 & 5 & 2100 & 7 & 6 \\
\hline Paracetamol & 140000 & 21 & 5 & 4600 & 39 & 6 \\
\hline Tramadol & 330 & 34 & 5 & 400 & 7 & 6 \\
\hline \multicolumn{7}{|c|}{ Antibiotics } \\
\hline Ciprofloxacin & 1300 & 27 & 5 & 1600 & 13 & 6 \\
\hline Clindamycin & 270 & 100 & 5 & 270 & 12 & 6 \\
\hline Levofloxacin & 25 & 4.7 & 3 & 22 & 13 & 6 \\
\hline Sulfamethoxazole & 12000 & 36 & 5 & 2500 & 19 & 6 \\
\hline Trimethoprim & 1400 & 34 & 5 & 290 & 14 & 6 \\
\hline \multicolumn{7}{|c|}{ Anticonvulsants } \\
\hline Carbamazepine & 480 & 22 & 5 & 480 & 3 & 6 \\
\hline Lamotrigine & 240 & 0 & 2 & 0 & - & 0 \\
\hline \multicolumn{7}{|c|}{ Antidiabetics } \\
\hline Gliclazide & - & - & 0 & 44 & 8 & 6 \\
\hline \multicolumn{7}{|c|}{ Antihypertensives } \\
\hline Atenolol & - & - & 0 & 580 & - & 1 \\
\hline Enalapril & 7600 & 16 & 5 & 8100 & 7 & 6 \\
\hline \multicolumn{7}{|c|}{ Antimycotics } \\
\hline Fluconazole & 730 & 32 & 5 & 1800 & 5 & 6 \\
\hline \multicolumn{7}{|c|}{ Antiretrovirals } \\
\hline Abacavir & 100 & 110 & 5 & 540 & 4 & 6 \\
\hline Atazanavir & 3100 & 14 & 5 & 3000 & 12 & 6 \\
\hline Darunavir & 14000 & 21 & 5 & 10000 & 11 & 6 \\
\hline Lamivudine & 74000 & 23 & 5 & 130000 & 15 & 6 \\
\hline Nevirapine & 350 & 13 & 5 & 350 & 16 & 6 \\
\hline Raltegravir & 4100 & 46 & 5 & 3500 & 10 & 6 \\
\hline \multicolumn{7}{|c|}{ Antivirals } \\
\hline Aciclovir & 3000 & 42 & 5 & 1900 & 29 & 6 \\
\hline \multicolumn{7}{|c|}{ Herbicides/Pesticides } \\
\hline Tebuthiuron & 96 & 22 & 5 & 110 & 14 & 6 \\
\hline Terbuthylazine & 41 & 31 & 4 & 53 & 15 & 5 \\
\hline \multicolumn{7}{|c|}{ Stimulants } \\
\hline Caffeine & 22000 & 22 & 5 & 7500 & 19 & 6 \\
\hline
\end{tabular}

${ }^{a}$ average concentration; ${ }^{b}$ relative standard deviation; ${ }^{c}$ number of detects

The antimycotic fluconazole was present in both influent and AF effluent samples at average concentrations of $730 \mathrm{ng} / \mathrm{L}$ and $1.8 \mu \mathrm{g} / \mathrm{L}$, respectively (Table 1 ). These concentrations exceed the PNEC for fluconazole of $250 \mathrm{ng} / \mathrm{L}$ (Bengtsson-Palme and Larsson, 2016).

The herbicide tebuthiuron was detected in all samples at average concentrations of 96 and $110 \mathrm{ng} / \mathrm{L}$ in the influent and AF effluent, respectively (Table 1). This report appears to be the first finding of tebuthiuron in domestic wastewater and could be due to exposure of clothing and/or ingestion during usage. It has been found at high concentrations in waters connected to sugarcane production in China (7-22 $\mu \mathrm{g} / \mathrm{L}$ ) (Qian et al., 2017) and in the Pardo River, São Paulo, Brazil (1 $\mu \mathrm{g} / \mathrm{L})$ (Machado et al., 2016). Another herbicide, terbuthylazine, was found in the samples from Days 2 and 3 (at $41 \mathrm{ng} / \mathrm{L}$ in the influent and $53 \mathrm{ng} / \mathrm{L}$ in the AF effluent, respectively). It has been detected in South African surface water associated with corn production and other agricultural use at concentrations ranging from 1.04 to $4.2 \mu \mathrm{g} / \mathrm{L}$ (Du Preez et al., 2005). It has also been found in ground and surface water in Slovenia (Koroša et al., 2016), Germany (Christoffels et al., 2016) and Spain (Robles-Molina et al., 2014), among others, all associated with agricultural run-off. Terbuthylazine is widely used in European countries and South Africa as a replacement for atrazine (Heri et al., 2008) and, as such, atrazine was not found in any of the samples investigated in this study.

Caffeine is naturally occurring in various plant species and used as a constituent in food, beverages, and an additive in common pain relievers. Due to its widespread consumption, caffeine is used as an anthropogenic marker for wastewater pollution (Buerge et al., 2003). Caffeine was present at average concentrations of 22 and $7.5 \mu \mathrm{g} / \mathrm{L}$ in all influent and AF effluent samples, respectively (Table 1). Similar concentrations were found in conventional WWTP influent $(15 \mu \mathrm{g} / \mathrm{L})$; however, AF effluent concentrations were about 10 -fold lower $(0.8 \mu \mathrm{g} / \mathrm{mL})$ (Archer et al., 2017). 


\section{Removal efficiencies}

On average, the compound class of antibiotics and analgesics/ anti-inflammatory drugs were most efficiently removed $(31 \%$ and $29 \%$, respectively). It is noteworthy that antiretrovirals, the second-most abundant class in influent, showed very poor REs (Table A9, Appendix).

Six compounds were removed with REs ranging from $<25$ to $97 \%$, and four compounds had REs that were larger than $60 \%$. These compounds include paracetamol (97\%), the two antibiotics sulfamethoxazole $(79 \%)$ and trimethoprim (79\%), and caffeine (66\%). Similar REs were reported for another decentralised system consisting of a septic tank and a drain field, with the exception of sulfamethoxazole which had a lower RE of $40 \%$ (Schaider et al., 2017). Comparable removal of MPs for DEWATS and conventional WWTPs has been reported previously (Blum et al., 2017; Gros et al., 2017).

No removal was observed for 15 compounds, or an increase in concentration was found in the AF effluent (negative REs). An increase in MP concentration through a treatment system has been widely reported. It is assumed to be associated with the biological and non-biological deconjugation of metabolites during wastewater treatment and the release of compounds accumulated in aggregates (Blair et al., 2015; Stadler et al., 2012; Verlicchi et al., 2012). In addition, our sampling strategy, grab sampling at set time-points, could be heavily influenced by a high variability in the system.

A majority of compounds with low or negative REs were reported to be more efficiently removed by other OWTS and WWTPs (comparison shown in Table A6, Appendix). This can partly be explained by the short retention time in this system. However, it should be noted that removal of MPs in this study was only evaluated from the AF effluent and not the final effluent (i.e., secondary treatment of the AF effluent in the hybrid subsurface flow CW system) (Fig. 1).

\section{Removal of MPs using biochars}

Twenty-four identified compounds present in the wastewater were used for the biochar removal tests. None of the compounds were detected in Milli-Q-blanks. As the internal standard ketoprofen-D3 was not visible in the biochar-treated water samples, fluconazole-D4 was instead used for the respective compounds.

Overall, all biochars were able to remove some of the targeted MPs (Table A9, Appendix) with the highest average REs of $62 \%$ for biochar produced from olive residues, followed by RF (53\%), tomato (46\%), and rice husks (44\%). Depending on the biochar, some compounds showed varying REs, with the widest range observed for clindamycin from $70 \%$ (olive) to $-73 \%$ (RF).

In total, 14 compounds had REs higher than $60 \%$ for olive biochar $(8,8$, and 7 for rice husk, RF, and tomato, respectively). Compounds with high REs for most biochars were the antibiotics ciprofloxacin, sulfamethoxazole, and trimethoprim, as well as terbuthylazine. It is noteworthy that for the two most dominant compound classes - antibiotics and antiretrovirals - olive biochar had the greatest average removal of 87 and $63 \%$, respectively, compared to tomato (87 and 46\%), rice husk (76 and 39\%) and RF (55 and 55\%). Apart from clindamycin, for all antibiotics, REs of $100 \%$ could be achieved by at least one of the biochars. Therefore, by introducing biochar adsorption as an additional treatment step, the posed risk of antimicrobial resistance by ciprofloxacin, that by far exceeded its PNEC in DEWATS effluent, could be significantly decreased.

Negative removal was only observed for a few compound/ char combinations ( 2 for rice husk, 1 for olive, tomato, and
RF, respectively). In total, only 2 compounds had a maximum removal lower than 30\%, namely, fluconazole (29\%) and enalapril (20\%) (Table A10, Appendix).

In conclusion, the implementation of a biochar filter in DEWATS would significantly decrease the total concentration of MPs in the AF effluent, especially the load of critical antibiotics and antiretrovirals, thus decreasing the risks to the receiving environment. To maximize the removal, it is anticipated that applying a mix of different biochars would be a suitable approach and should be assessed in future studies. Depending on the respective micropollutant pattern, combining biochar with different physical and chemical properties would allow for a wastewater treatment approach that meets the demands of the diversity of MP properties.

\section{CONCLUSIONS}

In this study, MP detection was done in the influent and AF effluent of a demonstration-scale DEWATS using a novel method LC-MS/ MS. Of 71 MPs detectable with this method, 24 MPs belonging to 10 compound classes were found in at least one sample. These MPs were generally detected at high concentrations, some of them exceeding those measured in other parts of the world. Highest concentrations were observed for analgesics/anti-inflammatory drugs, antiretrovirals, and antibiotics. Two compounds, the antibiotic ciprofloxacin and the antimycotic fluconazole, exceeded their PNEC in AF effluent. This may lead to antibiotic resistance.

This study showed that primary anaerobic treatment DEWATS is not effective in removing the identified MPs and that alternative measures need to be adopted to reduce the environmental concerns of discharging AF effluent without adequate MP removal. Future DEWATS in eThekwini are planned to be combined with flushing urine diversion (UD) toilets at the household level. Urine separation will prevent most of the MPs from entering the DEWATS.

In existing DEWATS, biochar may be a promising filter media to remove MPs from wastewater. In this study, the biochar from 4 different feedstocks was found to be able to efficiently remove a majority of the compounds (REs up to $100 \%$ ), with a maximum average removal of $62 \%$, concluding that biochar adsorption is a suitable option to enhance MP removal from anaerobically treated domestic wastewater.

However, the performance of the hybrid subsurface flow CW system for MP removal must be evaluated. Constructed wetlands are a common treatment option in DEWATS due to its buffering capacity to filter suspended solids and biologically reduce the nutrient content (especially nitrogen) through microbial degradation (nitrification/denitrification) and plant assimilation (Kadlec and Wallace, 2009; Stefanakis et al., 2014; Vymazal, 2010). More recently, CWs were found to be effective in the removal of antibiotics in China (Dan et al., 2020).

The performance of the CWs at the NM DEWATS has been evaluated. In their study, Arumugam and Buckley (2020) found that only nitrate was poorly removed from the CW system operating in series due to the lack of available biodegradable COD (bCOD) as a carbon source for denitrification in the HFCW. As a low-cost alternative, they suggested using plant-based carbon sources to aid in total nitrogen removal.

As for the selection of feedstock, as well as the technique used to produce the biochar, much more research is needed. Interestingly, the giant reed, Arundo donax, which is characterised as a Category $1 \mathrm{~b}$ invasive species in South Africa (implying that the plant must be removed and destroyed immediately) (DEA, 2016) is abundant on site at the NM DEWATS. Considered a waste biomass due to the large size of the species, A. donax has been used as a 
plant-based biochar in CWs for improved nitrogen removal (Li et al., 2018). Li et al. (2018) observed higher nitrate and total nitrogen removal in surface-flow CWs with a $20 \%$ plant-derived biochar than in those with $10 \%$ or no biochar.

Additional research is needed to ensure that DEWATS can produce fully compliant effluent for safe discharge to the environment, providing a sustainable option for non-sewered urban sanitation.

\section{ACKNOWLEDGEMENTS}

This research was funded by the Swedish Research Council under Grant No. 2015-03344. Alexandra Charlson at Umeå University is acknowledged for providing biochars. The authors also express their gratitude to Bio4Energy, a strategic research environment appointed by the Swedish Government, for supporting this work, and the eThekwini Water and Sanitation unit for access to the Newlands Mashu Research Site.

This paper is dedicated to the memory of the late Prof. Chris Buckley.

\section{REFERENCES}

ABAFE OA, SPÄTH J, FICK J, JANSSON S, BUCKLEY C, STARK A, PIETRUSCHKA B and MARTINCIGH BS (2018) LC-MS/MS determination of antiretroviral drugs in influents and effluents from wastewater treatment plants in KwaZulu-Natal, South Africa. Chemosphere. 200 660-670. https://doi.org/10.1016/j.chemo sphere.2018.02.105

AGUNBIADE FO and MOODLEY B (2014) Pharmaceuticals as emerging organic contaminants in Umgeni River water system, KwaZulu-Natal, South Africa. Environ. Monit. Assess. $1867273-$ 7291. https://doi.org/10.1007/s10661-014-3926-Z

ARCHER E, PETRIE B, KASPRZYK-HORDERN B and WOLFAARDT GM (2017) The fate of pharmaceuticals and personal care products (PPCPs), endocrine disrupting contaminants (EDCs), metabolites and illicit drugs in a WWTW and environmental waters. Chemosphere. 174 437-446. https://doi.org/10.1016/j.chemo sphere.2017.01.101

ARUMUGAM P and BUCKLEY CA (2020) Performance evaluation of constructed wetlands in a BORDA-designed decentralised wastewater treatment system. WRC Project No. K5/2579. WRC Report No. TT 812/20. Water Research Commission, Pretoria. ISBN 978-0-6392-0126-9.

BENGTSSON-PALME J and LARSSON DGJ (2016) Concentrations of antibiotics predicted to select for resistant bacteria: Proposed limits for environmental regulation. Environ. Int. 86 140-149. https://doi. org/10.1016/j.envint.2015.10.015

BLAIR B, NIKOLAUS A, HEDMAN C, KLAPER R and GRUNDL T (2015) Evaluating the degradation, sorption, and negative mass balances of pharmaceuticals and personal care products during wastewater treatment. Chemosphere. 134 395-401. https://doi.org/ 10.1016/j.chemosphere.2015.04.078

BLUM KM, ANDERSSON PL, RENMAN G, AHRENS L, GROS M, WIBERG K and HAGLUND P (2017) Non-target screening and prioritization of potentially persistent, bioaccumulating and toxic domestic wastewater contaminants and their removal in on-site and large-scale sewage treatment plants. Sci. Total Environ. 575 265-275. https://doi.org/10.1016/j.scitotenv.2016.09.135

BOUISSOU-SCHURTZ C, HOUETO P, GUERBET M, BACHELOT M, CASELLAS C, MAUCLAIRE A-C, PANETIER P, DELVAL C and MASSET D (2014) Ecological risk assessment of the presence of pharmaceutical residues in a French national water survey. Regul. Toxicol. Pharmacol. 69 296-303. https://doi.org/10.1016/j. yrtph.2014.04.006

BRODIN T, FICK J, JONSSON M and KLAMINDER J (2013) Dilute concentrations of a psychiatric drug alter behavior of fish from natural populations. Science $339814-815$. https://doi.org/10.1126/ science. 1226850

BUERGE IJ, POIGER T, MÜLLER MD and BUSER H-R (2003) Caffeine, an anthropogenic marker for wastewater contamination of surface waters. Environ. Sci. Technol. 37 691-700. https://doi.org/10.1021/ es $020125 z$
CHRISTOFFELS E, BRUNSCH A, WUNDERLICH-PFEIFFER J and MERTENS F (2016) Monitoring micropollutants in the Swist river basin. Water Sci. Technol. 74 2280-2296. https://doi.org/10.2166/ wst.2016.392

DAN A, ZHANG X, DAI Y, CHEN C and YANG Y (2020) Occurrence and removal of quinolone, tetracycline, and macrolide antibiotics from urban wastewater in constructed wetlands. J. Clean. Prod. 252 119677. https://doi.org/10.1016/j.jclepro.2019.119677

DEA (Department of Environmental Affairs, South Africa) (2016) National Environmental Management: Biodiversity Act, 2004 (Act No. 10 of 2004) Alien and Invasive species list. Government Gazette No. 40166. Government Printer, Pretoria.

DOH (Department of Health. Republic of South Africa) (2014) Essential Drugs Programme. Primary Healthcare Standard Treatment Guidelines and Essential Medicines List. $5^{\text {th }}$ edn. DOH, Pretoria.

DU PREEZ LH, JANSEN VAN RENSBURG PJ, JOOSTE AM, CARR JA, GIESY JP, GROSS TS, KENDALL RJ, SMITH EE, VAN DER KRAAK G and SOLOMON KR (2005) Seasonal exposures to triazine and other pesticides in surface waters in the western Highveld corn-production region in South Africa. Environ. Pollut. 135 131-141. https://doi.org/10.1016/j.envpol.2004.09.019

FALEYE AC, ADEGOKE AA, RAMLUCKAN K, FICK J, STENSTRÖM TA (2019) Concentration and reduction of antibiotic residues in selected wastewater treatment plants and receiving waterbodies in Durban, South Africa. Sci. Total Environ. 678 10-20. https://doi. org/10.1016/j.scitotenv.2019.04.410

GAGO-FERRERO P, GROS M, AHRENS L and WIBERG K (2017) Impact of on-site, small and large scale wastewater treatment facilities on levels and fate of pharmaceuticals, personal care products, artificial sweeteners, pesticides, and perfluoroalkyl substances in recipient waters. Sci. Total Environ. 601-602 12891297. https://doi.org/10.1016/j.scitotenv.2017.05.258

GCIS (Government Communication and Information System, South Africa) (2017) Offical guide to South Africa 2017/2018. GCIS, Pretoria.

GOLOVKO O, KUMAR V, FEDOROVA G, RANDAK T and GRABIC R (2014) Seasonal changes in antibiotics, antidepressants/psychiatric drugs, antihistamines and lipid regulators in a wastewater treatment plant. Chemosphere. 111 418-426. https://doi.org/10.1016/j.chemo sphere.2014.03.132

GOMES NA, PUDAGE AM, JOSHI SS, VAIDYA VV and PAREKH SA (2008) LC-MS-MS method for simultaneous analysis of abacavir and lamivudine in human plasma, and its application to a bioequivalence study. Chromatographia. 68 541-550. https://doi. org/10.1365/s10337-008-0789-x

GROS M, BLUM KM, JERNSTEDT H, RENMAN G, RODRÍGUEZMOZAZ S, HAGLUND P, ANDERSSON PL, WIBERG $\mathrm{K}$ and AHRENS L (2017) Screening and prioritization of micropollutants in wastewaters from on-site sewage treatment facilities. J. Hazardous Mater. 328 37-45. https://doi.org/10.1016/j.jhazmat.2016.12.055

GURKE R, RÖßLER M, MARX C, DIAMOND S, SCHUBERT S, OERTEL R and FAULER J (2015) Occurrence and removal of frequently prescribed pharmaceuticals and corresponding metabolites in wastewater of a sewage treatment plant. Sci. Total Environ. 532 762-770.https://doi.org/10.1016/j.scitotenv.2015.06.067 HERI W, CARROLL B, PARSHLEY T and NABORS JB (2008) Chapter 3 - Production, development, and registration of triazine herbicides. In: Lebaron HM, Mcfarland JE and Burnside OC (eds) The Triazine Herbicides. Elsevier, San Diego. https://doi.org/10.1016/B978-044 451167-6.50006-4

HOLLENDER J, ZIMMERMANN SG, KOEPKE S, KRAUSS M, MCARDELL CS, ORT C, SINGER H, VON GUNTEN U and SIEGRIST H (2009) Elimination of organic micropollutants in a municipal wastewater treatment plant upgraded with a full-scale post-ozonation followed by sand filtration. Environ. Sci. Technol. 43 7862-7869. https://doi.org/10.1021/es9014629

K'OREJE KO, DEMEESTERE K, DE WISPELAERE P, VERGEYNST L, DEWULF J and VAN LANGENHOVE H (2012) From multiresidue screening to target analysis of pharmaceuticals in water: Development of a new approach based on magnetic sector mass spectrometry and application in the Nairobi River basin, Kenya. Sci. Total Environ. 437 153-164. https://doi.org/10.1016/j. scitotenv.2012.07.052 
K'OREJE KO, VERGEYNST L, OMBAKA D, DE WISPELAERE P, OKOTH M, VAN LANGENHOVE H and DEMEESTERE K (2016) Occurrence patterns of pharmaceutical residues in wastewater, surface water and groundwater of Nairobi and Kisumu city Kenya. Chemosphere. 149 238-244. https://doi.org/10.1016/j.chemo sphere.2016.01.095

K'OREJE KO, KANDIE FJ, VERGEYNST L, ABIRA MA, VAN LANGENHOVE H, OKOTH M, DEMEESTERE K (2018) Occurrence, fate and removal of pharmaceuticals, personal care products and pesticides in wastewater stabilization ponds and receiving rivers in the Nzoia Basin, Kenya. Sci. Total Environ. 637 336-348. https://doi.org/10.1016/j.scitotenv.2018.04.331

K'OREJE KO, OKOTH M, VAN LANGENHOVE H, DEMEESTERE $\mathrm{K}$ (2020) Occurrence and treatment of contaminants of emerging concern in the African aquatic environment: Literature review and a look ahead. J. Environ. Manage. 254 109752. https://doi. org/10.1016/j.jenvman.2019.109752

KADLEC RH and WALLACE S (2009) Treatment Wetlands. CRC Press, Boca Raton. https://doi.org/10.1201/9781420012514

KOROŠA A, AUERSPERGER P and MALI N (2016) Determination of micro-organic contaminants in groundwater (Maribor, Slovenia) Sci. Total Environ. 571 1419-1431. https://doi.org/10.1016/j.scito tenv.2016.06.103

KYZAS GZ, FU J, LAZARIDIS NK, BIKIARIS DN and MATIS KA (2015) New approaches on the removal of pharmaceuticals from wastewaters with adsorbent materials. J. Mol. Liq. 209 87-93. https:// doi.org/10.1016/j.molliq.2015.05.025

LI J, FAN J, ZHANG J, HU Z and LIANG S (2018) Preparation and evaluation of wetland plant-based biochar for nitrogen removal enhancement in surface flow constructed wetlands. Environ. Sci. Pollut. Res. 25 13929-13937. https://doi.org/10.1007/s11356-018$1597-y$

LINDBERG RH, WENNBERG P, JOHANSSON MI, TYSKLIND M and ANDERSSON BAV (2005) Screening of human antibiotic substances and determination of weekly mass flows in five sewage treatment plants in Sweden. Environ. Sci. Technol. 39 3421-3429. https://doi.org/10.1021/es048143z

LINDBERG RH, ÖSTMAN M, OLOFSSON U, GRABIC R, FICK J (2014) Occurrence and behaviour of 105 active pharmaceutical ingredients in sewage waters of a municipal sewer collection system. Water Res. 58 221-229. https://doi.org/10.1016/j.watres.2014.03.076

LUO Y, GUO W, NGO HH, NGHIEM LD, HAI FI, ZHANG J, LIANG S and WANG XC (2014) A review on the occurrence of micropollutants in the aquatic environment and their fate and removal during wastewater treatment. Sci. Total Environ. 473 619-641. https://doi. org/10.1016/j.scitotenv.2013.12.065

MACHADO CS, ALVES RIS, FREGONESI BM, TONANI KAA, MARTINIS BS, SIERRA J, NADAL M, DOMINGO JL and SEGURA-MUÑOZ S (2016) Chemical contamination of water and sediments in the Pardo River, São Paulo, Brazil. Procedia Eng. 162 230-237. https://doi.org/10.1016/j.proeng.2016.11.046

MARGOT J, ROSSI L, BARRY D and HOLLIGER C (2015) A review of the fate of micropollutants in wastewater treatment plants. Wiley Interdisc. Rev. Water. 2 457-487. https://doi.org/10.1002/wat2.1090

MATONGO S, BIRUNGI G, MOODLEY B and NDUNGU P (2015a) Occurrence of selected pharmaceuticals in water and sediment of Umgeni River, KwaZulu-Natal, South Africa. Environ. Sci. Pollut. Res. 22 10298-10308. https://doi.org/10.1007/s11356-015-4217-0

MATONGO S, BIRUNGI G, MOODLEY B and NDUNGU P (2015b) Pharmaceutical residues in water and sediment of Msunduzi River KwaZulu-Natal, South Africa. Chemosphere. 134 133-140. https:// doi.org/10.1016/j.chemosphere.2015.03.093

MCCURRY DL, BEAR SE, BAE J, SEDLAK DL, MCCARTY PL and MITCH WA (2014) Superior removal of disinfection byproduct precursors and pharmaceuticals from wastewater in a staged anaerobic fluidized membrane bioreactor compared to activated sludge. Environ. Sci. Technol. Lett. 1 459-464. https://doi.org/ 10.1021/ez500279a

MOHAN D, SARSWAT A, OK YS and PITTMAN CU (2014) Organic and inorganic contaminants removal from water with biochar a renewable, low cost and sustainable adsorbent - a critical review. Bioresour. Technol. 160 191-202. https://doi.org/10.1016/j. biortech.2014.01.120
MURJUKI CW, HOME PG, RAUDE JM, NGUMBA EK, MUNALA GK, KAIRIGO PK, GACHANJA AN, TUHKANEN TA (2020) Occurrence, distribution, and risk assessment of pharmerciuticals in wastewater and open surface drains of peri-urban areas: Case study of Juja town, Kenya. Environ. Pollut. 267 115503. https://doi. org/10.1016/j.envpol.2020.115503

NORDIN A, POMMER L, STRANDBERG M and OLOFSSON I (2013) Biomass conversion through torrefaction. In: Dahlquist E (ed.) Technologies for Converting Biomass to Useful Energy: Combustion, Gasification, Pyrolysis, Torrefaction and Fermentation. CRC Press, Boca Raton. 217-244. https://doi.org/10.1201/b14561-8

ODINDO A, BAME I, MUSAZURA W, HUGHES J and BUCKLEY C (2016) Integrating agriculture in designing on-site, low cost sanitation technologies in social housing schemes. WRC Report No. TT 700/16. Water Research Commission. Pretoria.

OLUJIMI OO, FATOKI OS, ODENDAAL JP and DASO AP (2012) Chemical monitoring and temporal variation in levels of endocrine disrupting chemicals (priority phenols and phthalate esters) from selected wastewater treatment plant and freshwater systems in Republic of South Africa. Microchem. J. 101 11-23. https://doi. org/10.1016/j.microc.2011.09.011

OUYANG J, ZHOU L, LIU Z, HENG JYY and CHEN W (2020) Biomassderived activated carbons for the removal of pharmaceutical mircopollutants from wastewater: A review. Sep. Purif. Technol. 253 117536. https://doi.org/10.1016/j.seppur.2020.117536

PIAI L, BLOKLAND M, VAN DER WAL A and LANGENHOFF A (2020) Biodegradation and adsorption of micropollutants by biological activated carbon from a drinking water production plant. J. Hazardous Mater. 388 122028. https://doi.org/10.1016/j. jhazmat.2020.122028

PRASSE C, SCHLÜSENER MP, SCHULZ $R$ and TERNES TA (2010) Antiviral drugs in wastewater and surface waters: a new pharmaceutical class of environmental relevance? Environ. Sci. Technol. 44 1728-1735. https://doi.org/10.1021/es903216p

QIAN Y, MATSUMOTO H, LIU X, LI S, LIANG X, LIU Y, ZHU G and WANG M (2017) Dissipation, occurrence and risk assessment of a phenylurea herbicide tebuthiuron in sugarcane and aquatic ecosystems in South China. Environ. Pollut. 227 389-396. https:// doi.org/10.1016/j.envpol.2017.04.082

REUNGOAT J, ESCHER BI, MACOVA M, ARGAUD FX, GERNJAK W and KELLER J (2012) Ozonation and biological activated carbon filtration of wastewater treatment plant effluents. Water Res. 46863 872. https://doi.org/10.1016/j.watres.2011.11.064

ROBLES-MOLINA J, GILBERT-LÓPEZ B, GARCÍA-REYES JF and MOLINA-DÍAZ A (2014) Monitoring of selected priority and emerging contaminants in the Guadalquivir River and other related surface waters in the province of Jaén, South East Spain. Sci. Total Environ. 479-480 247-257. https://doi.org/10.1016/j. scitotenv.2014.01.121

ROMA E, PHILP K, BUCKLEY C, XULU S and SCOTT D (2013) User perceptions of urine diversion dehydration toilets: Experiences from a cross-sectional study in eThekwini Municipality. Water SA. 39 302-312. https://doi.org/10.4314/wsa.v39i2.15

ROSSMANN J, SCHUBERT S, GURKE R, OERTEL R and KIRCH W (2014) Simultaneous determination of most prescribed antibiotics in multiple urban wastewater by SPE-LC-MS/MS. J. Chromatogr. B. 969 162-170. https://doi.org/10.1016/j.jchromb.2014.08.008

SCHAIDER LA, RODGERS KM and RUDEL RA (2017) Review of organic wastewater compound concentrations and removal in onsite wastewater treatment systems. Environ. Sci. \& Technol. 51 7304-7317. https://doi.org/10.1021/acs.est.6b04778

SIMBAYI LC, ZUMA K, ZUNGU N, MOYO S, MARINDA E, JOOSTE S, MABASO M, RAMLAGAN S, NORTH A, VAN ZY LJ, MOHLABANE N, DIETRICH C and NAIDOO I (2019) South African National HIV Prevalence, Incidence, Behaviour and Communication Survey, 2017. HSRC Press, Cape Town.

STADLER L, ERNSTOFF A, AGA D and LOVE N (2012) Micropollutant fate in wastewater treatment: redefining "removal". Environ. Sci. Technol. 46 10485-6. https://doi.org/10.1021/es303478w

STEFANAKIS A, AKRATOS CS and TSIHRINTZIS VA (2014) Vertical Flow Constructed Wetlands: Eco-Engineering Systems for Wastewater and Sludge Treatment. Newnes, Oxford, UK. https://doi.org/10.1016/ B978-0-12-404612-2.00008-8 
THOMPSON KA, SHIMABUKU KK, KEARNS JP, KNAPPE DRU, SUMMERS RS and COOK SM (2016) Environmental comparison of biochar and activated carbon for tertiary wastewater treatment. Environ. Sci. Technol. 50 11253-11262. https://doi.org/10.1021/acs. est.6b03239

UNAIDS (2021) Start Free, Stay Free, AIDS Free - Final report on 2020 targets, July 2021 URL: https://www.unaids.org/en/resources/ documents/2021/start-free-stay-free-aids-free-final-report-on-2020targets

VAN BOECKEL TP, GANDRA S, ASHOK A, CAUDRON Q GRENFELL BT, LEVIN SA and LAXMINARAYAN R (2014) Global antibiotic consumption 2000 to 2010: an analysis of national pharmaceutical sales data. Lancet Infect. Dis. 14 742-750. https:// doi.org/10.1016/S1473-3099(14)70780-7

VAN DER STELT MJC, GERHAUSER H, KIEL JHA and PTASINSKI KJ (2011) Biomass upgrading by torrefaction for the production of biofuels: A review. Biomass Bioenerg. 35 3748-3762. https://doi. org/10.1016/j.biombioe.2011.06.023

VERLICCHI P, AL AUKIDY M and ZAMBELLO E (2012) Occurrence of pharmaceutical compounds in urban wastewater: Removal, mass load and environmental risk after a secondary treatment - A review. Sci. Total Environ. 429 123-155. https://doi.org/10.1016/j. scitotenv.2012.04.028

VYMAZAL J (2010) Constructed wetlands for wastewater treatment. Water. 2 530. https://doi.org/10.3390/w2030530

VYMAZAL J, DVOŘÁKOVÁ BŘEZINOVÁ T, KOŽELUH $\mathrm{M}$ and KULE L (2017) Occurrence and removal of pharmaceuticals in four full-scale constructed wetlands in the Czech Republic - the first year of monitoring. Ecol. Eng. 98 354-364. https://doi.org/10.1016/j. ecoleng.2016.08.010
WANDA EM, NYONI H, MAMBA BB and MSAGATI TA (2017) Occurrence of emerging micropollutants in water systems in Gauteng, Mpumalanga, and North West Provincs, South Africa. Int. J. Environ. Res. Public Health. 14. https://doi.org/10.3390/ ijerph14010079

WEIDEMANN E, NIINIPUU M, FICK J and JANSSON S (2018) Using carbonized low-cost materials for removal of chemicals of environmental concern from water. Environ. Sci. Pollut. Res. 25 15793-15801. https://doi.org/10.1007/s11356-018-1781-0

WOODING M, ROHWER ER and NAUDÉ Y (2017) Determination of endocrine disrupting chemicals and antiretroviral compounds in surface water: A disposable sorptive sampler with comprehensive gas chromatography - Time-of-flight mass spectrometry and large volume injection with ultra-high performance liquid chromatography-tandem mass spectrometry. J. Chromatogr. A. 1496 122-132. https://doi.org/10.1016/j.chroma.2017.03.057

YANG Y, OK YS, KIM K-H, KWON EE and TSANG YF (2017) Occurrences and removal of pharmaceuticals and personal care products (PPCPs) in drinking water and water/sewage treatment plants: a review. Sci. Total Environ. 596 303-320. https://doi.org/ 10.1016/j.scitotenv.2017.04.102 
Table A1. CAS number, formula, and supplier for all analytes and internal standards

\begin{tabular}{|c|c|c|c|}
\hline Compound & CAS & Formula & Supplier \\
\hline \multicolumn{4}{|c|}{ Analgesics/anti-inflammatory drugs } \\
\hline Betamethasone & $378-44-9$ & $\mathrm{C}_{22} \mathrm{H}_{29} \mathrm{FO}_{5}$ & Sigma-Aldrich \\
\hline Betamethasone-17,21-dipropionate & $5593-20-4$ & $\mathrm{C}_{28} \mathrm{H}_{37} \mathrm{FO}_{7}$ & Sigma-Aldrich \\
\hline Betamethasone-17-valerate & $2152-44-5$ & $\mathrm{C}_{27} \mathrm{H}_{37} \mathrm{FO}_{6}$ & Sigma-Aldrich \\
\hline Budesonide & $51333-22-3$ & $\mathrm{C}_{25} \mathrm{H}_{34} \mathrm{O}_{6}$ & Sigma-Aldrich \\
\hline Codeine & $76-57-3$ & $\mathrm{C}_{18} \mathrm{H}_{21} \mathrm{NO}_{3}$ & Sigma-Aldrich \\
\hline Diclofenac & $15307-79-6$ & $\mathrm{C}_{14} \mathrm{H}_{10} \mathrm{Cl}_{2} \mathrm{NNaO}_{2}$ & Sigma-Aldrich \\
\hline Ketoprofen & $22071-15-4$ & $\mathrm{C}_{16} \mathrm{H}_{14} \mathrm{O}_{3}$ & Sigma-Aldrich \\
\hline Paracetamol & $103-90-2$ & $\mathrm{C}_{8} \mathrm{H}_{9} \mathrm{NO}_{2}$ & Sigma-Aldrich \\
\hline Tramadol & $36282-47-0$ & $\mathrm{C}_{16} \mathrm{H}_{25} \mathrm{NO}_{2}$ & Sigma-Aldrich \\
\hline \multicolumn{4}{|c|}{ Antiarrhythmics } \\
\hline Carvedilol & 72956-09-3 & $\mathrm{C}_{24} \mathrm{H}_{26} \mathrm{~N}_{2} \mathrm{O}_{4}$ & Sigma-Aldrich \\
\hline Lignocaine & $137-58-6$ & $\mathrm{C}_{14} \mathrm{H}_{22} \mathrm{~N}_{2} \mathrm{O}$ & Sigma-Aldrich \\
\hline \multicolumn{4}{|c|}{ Antibiotics } \\
\hline Amoxicillin & $26787-78-0$ & $\mathrm{C}_{16} \mathrm{H}_{19} \mathrm{~N}_{3} \mathrm{O}_{5} \mathrm{~S}$ & Sigma-Aldrich \\
\hline Ciprofloxacin & $85721-33-1$ & $\mathrm{C}_{17} \mathrm{H}_{18} \mathrm{FN}_{3} \mathrm{O}_{3}$ & Sigma-Aldrich \\
\hline Clindamycin & $21462-39-5$ & $\mathrm{C}_{18} \mathrm{H}_{33} \mathrm{CIN}_{2} \mathrm{O}_{5} \mathrm{~S}$ & Sigma-Aldrich \\
\hline Erythromycin & $114-07-8$ & $\mathrm{C}_{37} \mathrm{H}_{67} \mathrm{NO}_{13}$ & Sigma-Aldrich \\
\hline Flucloxacillin & $1847-24-1$ & $\mathrm{C}_{19} \mathrm{H}_{17} \mathrm{ClFN}_{3} \mathrm{O}_{5} \mathrm{~S}$ & Sigma-Aldrich \\
\hline Levofloxacin & $100986-85-4$ & $\mathrm{C}_{18} \mathrm{H}_{20} \mathrm{FN}_{3} \mathrm{O}_{4}$ & Sigma-Aldrich \\
\hline Linezolid & $165800-03-3$ & $\mathrm{C}_{16} \mathrm{H}_{20} \mathrm{FN}_{3} \mathrm{O}_{4}$ & LGC Standards \\
\hline Nalidixic acid & $389-08-2$ & $\mathrm{C}_{12} \mathrm{H}_{12} \mathrm{~N}_{2} \mathrm{O}_{3}$ & Sigma-Aldrich \\
\hline Sulfamethazine & $57-68-1$ & $\mathrm{C}_{12} \mathrm{H}_{14} \mathrm{~N}_{4} \mathrm{O}_{2} \mathrm{~S}$ & Sigma-Aldrich \\
\hline Sulfamethoxazole & $723-46-6$ & $\mathrm{C}_{10} \mathrm{H}_{11} \mathrm{~N}_{3} \mathrm{O}_{3} \mathrm{~S}$ & Riedel-de Haen \\
\hline Trimethoprim & $738-70-5$ & $\mathrm{C}_{14} \mathrm{H}_{18} \mathrm{~N}_{4} \mathrm{O}_{3}$ & Sigma-Aldrich \\
\hline Virginiamycin & 21411-53-0 & $\mathrm{C}_{2} 8 \mathrm{H}_{35} \mathrm{~N}_{3} \mathrm{O}_{7}$ & Sigma-Aldrich \\
\hline \multicolumn{4}{|c|}{ Anticholinergics } \\
\hline Atropine & $51-55-8$ & $\mathrm{C}_{17} \mathrm{H}_{23} \mathrm{NO}_{3}$ & Sigma-Aldrich \\
\hline Biperiden & $1235-82-1$ & $\mathrm{C}_{21} \mathrm{H}_{30} \mathrm{CINO}$ & Sigma-Aldrich \\
\hline Orphenadrine & 83-98-7 & $\mathrm{C}_{18} \mathrm{H}_{23} \mathrm{NO}$ & LGC Standards \\
\hline \multicolumn{4}{|c|}{ Anticonvulsants } \\
\hline Acetazolamide & $59-66-5$ & $\mathrm{C}_{4} \mathrm{H}_{6} \mathrm{~N}_{4} \mathrm{O}_{3} \mathrm{~S}_{2}$ & Sigma-Aldrich \\
\hline Carbamazepine & $298-46-4$ & $\mathrm{C}_{15} \mathrm{H}_{12} \mathrm{~N}_{2} \mathrm{O}$ & Sigma-Aldrich \\
\hline Lamotrigine & 84057-84-1 & $\mathrm{C}_{9} \mathrm{H}_{7} \mathrm{Cl}_{2} \mathrm{~N}_{5}$ & Sigma-Aldrich \\
\hline Phenytoin & $57-41-0$ & $\mathrm{C}_{15} \mathrm{H}_{12} \mathrm{~N}_{2} \mathrm{O}_{2}$ & Sigma-Aldrich \\
\hline \multicolumn{4}{|c|}{ Antidiabetics } \\
\hline Glibenclamide & $10238-21-8$ & $\mathrm{C}_{23} \mathrm{H}_{28} \mathrm{CIN}_{3} \mathrm{O}_{5} \mathrm{~S}$ & Sigma-Aldrich \\
\hline Gliclazide & 21187-98-4 & $\mathrm{C}_{15} \mathrm{H}_{21} \mathrm{~N}_{3} \mathrm{O}_{3} \mathrm{~S}$ & Sigma-Aldrich \\
\hline \multicolumn{4}{|c|}{ Antidotes } \\
\hline Naloxone & $465-65-6$ & $\mathrm{C}_{19} \mathrm{H}_{21} \mathrm{NO}_{4}$ & Sigma-Aldrich \\
\hline \multicolumn{4}{|c|}{ Antihistamines } \\
\hline Antazoline & $2508-72-7$ & $\mathrm{C}_{17} \mathrm{H}_{19} \mathrm{~N}_{3}$ & Sigma-Aldrich \\
\hline Cetirizine & $83881-52-1$ & $\mathrm{C}_{21} \mathrm{H}_{25} \mathrm{CIN}_{2} \mathrm{O}_{3}$ & Sigma-Aldrich \\
\hline Chlorpheniramine & $113-92-8$ & $\mathrm{C}_{16} \mathrm{H}_{19} \mathrm{CIN}_{2}$ & Sigma-Aldrich \\
\hline Cimetidine & $51481-61-9$ & $\mathrm{C}_{10} \mathrm{H}_{16} \mathrm{~N}_{6} \mathrm{~S}$ & Sigma-Aldrich \\
\hline Promethazine & $58-33-3$ & $\mathrm{C}_{17} \mathrm{H}_{20} \mathrm{~N}_{2} \mathrm{~S}$ & Sigma-Aldrich \\
\hline \multicolumn{4}{|c|}{ Antihypertensives } \\
\hline Atenolol & $29122-68-7$ & $\mathrm{C}_{14} \mathrm{H}_{22} \mathrm{~N}_{2} \mathrm{O}_{3}$ & Sigma-Aldrich \\
\hline Bezafibrate & $41859-67-0$ & $\mathrm{C}_{19} \mathrm{H}_{20} \mathrm{CINO}_{4}$ & Sigma-Aldrich \\
\hline Enalapril & $84680-54-6$ & $\mathrm{C}_{18} \mathrm{H}_{24} \mathrm{~N}_{2} \mathrm{O}_{5}$ & LGC Standards \\
\hline Nifedipine & $21829-25-4$ & $\mathrm{C}_{17} \mathrm{H}_{18} \mathrm{~N}_{2} \mathrm{O}_{6}$ & Sigma-Aldrich \\
\hline \multicolumn{4}{|c|}{ Antimycotics } \\
\hline Clotrimazole & $23593-75-1$ & $\mathrm{C}_{22} \mathrm{H}_{17} \mathrm{CIN}_{2}$ & Sigma-Aldrich \\
\hline Fluconazole & 86386-73-4 & $\mathrm{C}_{13} \mathrm{H}_{12} \mathrm{~F}_{2} \mathrm{~N}_{6} \mathrm{O}$ & Sigma-Aldrich \\
\hline \multicolumn{4}{|c|}{ Antiparasitics } \\
\hline Albendazole & $54965-21-8$ & $\mathrm{C}_{12} \mathrm{H}_{15} \mathrm{~N}_{3} \mathrm{O}_{2} \mathrm{~S}$ & Sigma-Aldrich \\
\hline
\end{tabular}


Table A1 continued. CAS number, formula, and supplier for all analytes and internal standards

\begin{tabular}{|c|c|c|c|}
\hline Compound & CAS & Formula & Supplier \\
\hline \multicolumn{4}{|c|}{ Antiretrovirals } \\
\hline Abacavir & $188062-50-2$ & $\mathrm{C}_{28} \mathrm{H}_{36} \mathrm{~N}_{12} \mathrm{O}_{2}$ & Sigma-Aldrich \\
\hline Atazanavir & 229975-97-7 & $\mathrm{C}_{38} \mathrm{H}_{52} \mathrm{~N}_{6} \mathrm{O}_{7}$ & Sigma-Aldrich \\
\hline Darunavir & 206361-99-1 & $\mathrm{C}_{27} \mathrm{H}_{37} \mathrm{~N}_{3} \mathrm{O}_{7} \mathrm{~S}$ & Sigma-Aldrich \\
\hline Etravirine & $269055-15-4$ & $\mathrm{C}_{20} \mathrm{H}_{15} \mathrm{BrN}_{6} \mathrm{O}$ & LGC Standards \\
\hline Lamivudine & $134678-17-4$ & $\mathrm{C}_{8} \mathrm{H}_{11} \mathrm{~N}_{3} \mathrm{O}_{3} \mathrm{~S}$ & Sigma-Aldrich \\
\hline Nevirapine & $129618-40-2$ & $\mathrm{C}_{15} \mathrm{H}_{14} \mathrm{~N}_{4} \mathrm{O}$ & Sigma-Aldrich \\
\hline Raltegravir & $871038-72-1$ & $\mathrm{C}_{20} \mathrm{H}_{20} \mathrm{FKN}_{6} \mathrm{O}_{5}$ & Sigma-Aldrich \\
\hline Saquinavir & $149845-06-7$ & $\mathrm{C}_{38} \mathrm{H}_{50} \mathrm{~N}_{6} \mathrm{O}_{5}$ & Sigma-Aldrich \\
\hline \multicolumn{4}{|c|}{ Antivirals } \\
\hline Aciclovir & $59277-89-3$ & $\mathrm{C}_{8} \mathrm{H}_{11} \mathrm{~N}_{5} \mathrm{O}_{3}$ & Sigma-Aldrich \\
\hline Famciclovir & $104227-87-4$ & $\mathrm{C}_{14} \mathrm{H}_{19} \mathrm{~N}_{5} \mathrm{O}_{4}$ & Sigma-Aldrich \\
\hline \multicolumn{4}{|c|}{ Decongestants } \\
\hline Oxymetazoline & $1491-59-4$ & $\mathrm{C}_{16} \mathrm{H}_{24} \mathrm{~N}_{2} \mathrm{O}$ & Sigma-Aldrich \\
\hline \multicolumn{4}{|c|}{ Herbicides/pesticides } \\
\hline Atrazine & $1912-24-9$ & $\mathrm{C}_{8} \mathrm{H}_{14} \mathrm{ClN}_{5}$ & Sigma-Aldrich \\
\hline Tebuthiuron & $34014-18-1$ & $\mathrm{C}_{9} \mathrm{H}_{16} \mathrm{~N}_{4} \mathrm{OS}$ & Sigma-Aldrich \\
\hline Terbuthylazine & $5915-41-3$ & $\mathrm{C}_{9} \mathrm{H}_{16} \mathrm{CIN}_{5}$ & Sigma-Aldrich \\
\hline \multicolumn{4}{|c|}{ Hormonal contraceptives } \\
\hline Levonorgestrel & $797-63-7$ & $\mathrm{C}_{21} \mathrm{H}_{28} \mathrm{O}_{2}$ & LGC Standards \\
\hline Medroxyprogesterone & $520-85-4$ & $\mathrm{C}_{22} \mathrm{H}_{32} \mathrm{O}_{3}$ & Sigma-Aldrich \\
\hline Norgestrel & $6533-00-2$ & $\mathrm{C}_{21} \mathrm{H}_{28} \mathrm{O}_{2}$ & Sigma-Aldrich \\
\hline Progesterone & $57-83-0$ & $\mathrm{C}_{21} \mathrm{H}_{30} \mathrm{O}_{2}$ & Sigma-Aldrich \\
\hline \multicolumn{4}{|c|}{ Psycholeptics/antidepressants } \\
\hline Amitriptyline & $549-18-8$ & $\mathrm{C}_{20} \mathrm{H}_{23} \mathrm{~N}$ & Sigma-Aldrich \\
\hline Clozapine & $5786-21-0$ & $\mathrm{C}_{18} \mathrm{H}_{19} \mathrm{CIN}_{4}$ & Sigma-Aldrich \\
\hline Diazepam & $439-14-5$ & $\mathrm{C}_{16} \mathrm{H}_{13} \mathrm{CIN}_{2} \mathrm{O}$ & LGC Standards \\
\hline Fluoxetine & $56296-78-7$ & $\mathrm{C}_{17} \mathrm{H}_{18} \mathrm{~F}_{3} \mathrm{NO}$ & Sigma-Aldrich \\
\hline Haloperidol & $52-86-8$ & $\mathrm{C}_{21} \mathrm{H}_{23} \mathrm{CIFNO}_{2}$ & Sigma-Aldrich \\
\hline Lorazepam & $846-49-1$ & $\mathrm{C}_{15} \mathrm{H}_{10} \mathrm{Cl}_{2} \mathrm{~N}_{2} \mathrm{O}_{2}$ & BP Laboratory \\
\hline Oxazepam & $604-75-1$ & $\mathrm{C}_{15} \mathrm{H}_{11} \mathrm{CIN}_{2} \mathrm{O}_{2}$ & Sigma-Aldrich \\
\hline \multicolumn{4}{|c|}{ Stimulants } \\
\hline Caffeine & $58-08-2$ & $\mathrm{C}_{8} \mathrm{H}_{10} \mathrm{~N}_{4} \mathrm{O}_{2}$ & Sigma-Aldrich \\
\hline \multicolumn{4}{|c|}{ Internal standards } \\
\hline Atazanavir-D5 & $1132747-14-8$ & $\mathrm{C}_{38} \mathrm{H}_{47} \mathrm{D}_{5} \mathrm{~N}_{6} \mathrm{O}_{7}$ & Toronto Research Chemicals \\
\hline Carbamazepine-D10 & $132183-78-9$ & $\mathrm{C}_{15} \mathrm{D}_{10} \mathrm{H}_{2} \mathrm{~N}_{2} \mathrm{O}$ & Sigma-Aldrich \\
\hline Clindamycin-D3 & $1356933-72-6$ & $\mathrm{C}_{18} \mathrm{H}_{30} \mathrm{D}_{3} \mathrm{CIN}_{2} \mathrm{O}_{5} \mathrm{~S}$ & LGC Standards \\
\hline Codeine-D6 & $1007844-34-9$ & $\mathrm{C}_{18} \mathrm{H}_{15} \mathrm{D}_{6} \mathrm{NO}_{3}$ & Sigma-Aldrich \\
\hline Darunavir-D9 & $1133378-37-6$ & $\mathrm{C}_{27} \mathrm{H}_{28} \mathrm{D}_{9} \mathrm{~N}_{3} \mathrm{O}_{7} \mathrm{~S}$ & Toronto Research Chemicals \\
\hline Fluconazole-D4 & $1124197-58-5$ & $\mathrm{C}_{13} \mathrm{D}_{4} \mathrm{H}_{8} \mathrm{~F}_{2} \mathrm{~N}_{6} \mathrm{O}$ & Sigma-Aldrich \\
\hline Ketoprofen-D3 & $159490-55-8$ & $\mathrm{C}_{16} \mathrm{D}_{3} \mathrm{H}_{11} \mathrm{O}_{3}$ & Sigma-Aldrich \\
\hline Oxazepam-D5 & $65854-78-6$ & $\mathrm{C}_{15} \mathrm{H}_{6} \mathrm{D}_{5} \mathrm{CIN}_{2} \mathrm{O}_{2}$ & Sigma-Aldrich \\
\hline Sulfamethoxazole-D4 & $1020719-86-1$ & $\mathrm{C}_{10} \mathrm{H}_{7} \mathrm{D}_{4} \mathrm{~N}_{3} \mathrm{O}_{3} \mathrm{~S}$ & LGC Standards \\
\hline Tramadol-13C-D3 & NA & ${ }^{13} \mathrm{CC}_{15} \mathrm{D}_{3} \mathrm{H}_{22} \mathrm{NO}_{2}$ & Sigma-Aldrich \\
\hline Trimethoprim-13C-D3 & NA & ${ }^{13} \mathrm{C}_{13} \mathrm{CH}_{15} \mathrm{D}_{3} \mathrm{~N}_{4} \mathrm{O}_{3}$ & Cambridge Isotope Laboratories \\
\hline
\end{tabular}

Table A2. Gradient program for on-line SPE and LC

\begin{tabular}{|c|c|c|c|}
\hline Time (min) & $A(\%)$ & B (\%) & Flow (mL/min) \\
\hline \multicolumn{4}{|c|}{ On-line SPE } \\
\hline 0.00 & 100 & 0 & 0.00 \\
\hline 0.01 & 100 & 0 & 1.00 \\
\hline 2.00 & 100 & 0 & 1.00 \\
\hline 2.10 & 0 & 100 & 2.00 \\
\hline 4.00 & 0 & 100 & 2.00 \\
\hline 4.10 & 100 & 0 & 1.00 \\
\hline 7.00 & 100 & 0 & 1.00 \\
\hline \multicolumn{4}{|c|}{ LC } \\
\hline 0.00 & 90 & 10 & 0.20 \\
\hline 3.00 & 90 & 10 & 0.20 \\
\hline 6.00 & 0 & 100 & 0.25 \\
\hline 8.00 & 0 & 100 & 0.25 \\
\hline 8.01 & 90 & 10 & 0.20 \\
\hline 10.00 & 90 & 10 & 0.20 \\
\hline
\end{tabular}


Table A3. MS/MS transitions, collision energies, tube lenses, associated internal standards, and retention times for all analytes

\begin{tabular}{|c|c|c|c|c|c|c|c|c|c|}
\hline Compound & Internal standard & $\begin{array}{l}\text { Precursor } \\
(\mathrm{m} / \mathrm{z})\end{array}$ & $\begin{array}{c}\text { Product } \\
\text { ion }(\mathrm{m} / \mathrm{z}) 1\end{array}$ & $\begin{array}{c}\text { Collision } \\
\text { energy (V) } 1\end{array}$ & $\begin{array}{l}\text { RF Lens } \\
\text { (V) } 1\end{array}$ & $\begin{array}{c}\text { Product } \\
\text { ion } \mathrm{m} / \mathrm{z}) 2\end{array}$ & $\begin{array}{c}\text { Collision } \\
\text { energy }(V) 2\end{array}$ & $\begin{array}{l}\text { RF Lens } \\
\text { (V) } 2\end{array}$ & $\begin{array}{l}\text { Retention } \\
\text { time (min) }\end{array}$ \\
\hline \multicolumn{10}{|c|}{ Analgesics/anti-inflammatory drugs } \\
\hline Betamethasone & Codeine-D6 & 393.2 & 355.2 & 10 & 37 & 373.2 & 10 & 37 & 6.2 \\
\hline $\begin{array}{l}\text { Betamethasone-17, } \\
\text { 21-dipropionate }\end{array}$ & Codeine-D6 & 505.3 & 279.1 & 16 & 52 & 411.2 & 10 & 52 & 5.5 \\
\hline $\begin{array}{l}\text { Betamethasone-17- } \\
\text { valerate }\end{array}$ & Codeine-D6 & 477.3 & 279.2 & 17 & 47 & 355.2 & 10 & 47 & 6.1 \\
\hline Budesonide & Tramadol-13C-D3 & 431.2 & 323.1 & 10 & 46 & 413.2 & 10 & 46 & 5.9 \\
\hline Codeine & Codeine-D6 & 300.2 & 165 & 39 & 80 & 215.1 & 25 & 80 & 4 \\
\hline Diclofenac & Codeine-D6 & 296 & 215 & 19 & 47 & 214 & 35 & 47 & 6.1 \\
\hline Ketoprofen & Ketoprofen-D3 & 255.1 & 105.1 & 22 & 56 & 209 & 13 & 56 & 5.8 \\
\hline Paracetamol & Codeine-D6 & 152.1 & 93.06 & 23 & 46 & 110.1 & 15 & 46 & 3.5 \\
\hline Tramadol & Tramadol-13C-D3 & 264.2 & 246.1 & 10 & 44 & 58.1 & 17 & 44 & 5 \\
\hline \multicolumn{10}{|c|}{ Antiarrhythmics } \\
\hline Carvedilol & Tramadol-13C-D3 & 407.2 & 222.1 & 24 & 81 & 224.1 & 21 & 81 & 5.4 \\
\hline Lignocaine & Codeine-D6 & 235.2 & 58.17 & 32 & 48 & 86.1 & 17 & 48 & 4.8 \\
\hline \multicolumn{10}{|c|}{ Antibiotics } \\
\hline Amoxicillin & Codeine-D6 & 381.1 & 255 & 21 & 75 & 349.1 & 13 & 75 & 4.7 \\
\hline Ciprofloxacin & Clindamycin-D3 & 332.1 & 314.1 & 21 & 71 & 288 & 17 & 71 & 4.8 \\
\hline Clindamycin & Clindamycin-D3 & 425.2 & 377.2 & 18 & 83 & 126.2 & 28 & 83 & 5.1 \\
\hline Erythromycin & Tramadol-13C-D3 & 716.4 & 158.1 & 27 & 89 & 558.3 & 16 & 89 & 5.4 \\
\hline Flucloxacillin & Tramadol-13C-D3 & 486.1 & 454.1 & 16 & 74 & 160.1 & 18 & 74 & 5.8 \\
\hline Levofloxacin & Oxazepam-D5 & 362.1 & 261.1 & 26 & 73 & 318.1 & 18 & 73 & 4.8 \\
\hline Linezolid & Tramadol-13C-D3 & 338.2 & 195 & 23 & 83 & 296.1 & 17 & 83 & 5.1 \\
\hline Nalidixic acid & Ketoprofen-D3 & 233.1 & 187 & 25 & 57 & 215.1 & 14 & 57 & 5.6 \\
\hline Sulfamethazine & Codeine-D6 & 279.1 & 124 & 25 & 65 & 186 & 16 & 65 & 4.9 \\
\hline Sulfamethoxazole & Sulfamethoxaxole-D4 & 254 & 108.1 & 24 & 54 & 156 & 16 & 54 & 5.2 \\
\hline Trimethoprim & Trimethoprim-13C-D3 & 291.1 & 261 & 24 & 79 & 230.1 & 24 & 79 & 4.8 \\
\hline Virginiamycin & Ketoprofen-D3 & 526.2 & 355.1 & 17 & 68 & 508.3 & 11 & 68 & 5.6 \\
\hline \multicolumn{10}{|c|}{ Anticholinergics } \\
\hline Atropine & Codeine-D6 & 290.2 & 93.04 & 29 & 73 & 124.1 & 23 & 73 & 4.9 \\
\hline Biperiden & Tramadol-13C-D3 & 312.2 & 294.2 & 15 & 58 & 98.1 & 21 & 58 & 5.5 \\
\hline Orphenadrine & Tramadol-13C-D3 & 270.2 & 165 & 46 & 34 & 181 & 10 & 34 & 5.4 \\
\hline \multicolumn{10}{|c|}{ Anticonvulsants } \\
\hline Acetazolamide & Codeine-D6 & 223 & 163.9 & 21 & 47 & 180.9 & 13 & 47 & 3.9 \\
\hline Carbamazepine & Carbamazepine-D10 & 237 & 192.1 & 23 & 60 & 194.1 & 19 & 60 & 5.5 \\
\hline Lamotrigine & Carbamazepine-D10 & 256 & 159 & 29 & 82 & 210.9 & 26 & 82 & 5 \\
\hline Phenytoin & Tramadol-13C-D3 & 253.1 & 171 & 16 & 51 & 182.1 & 17 & 51 & 5.5 \\
\hline \multicolumn{10}{|c|}{ Antidiabetics } \\
\hline Glibenclamide & Codeine-D6 & 494.1 & 169 & 32 & 55 & 369.1 & 13 & 55 & 6 \\
\hline Gliclazide & Tramadol-13C-D3 & 324.2 & 110.1 & 22 & 62 & 127.1 & 18 & 62 & 5.9 \\
\hline \multicolumn{10}{|c|}{ Antidotes } \\
\hline Naloxone & Codeine-D6 & 328.1 & 212 & 39 & 66 & 310.1 & 18 & 66 & 3.9 \\
\hline \multicolumn{10}{|c|}{ Antihistamines } \\
\hline Antazoline & Tramadol-13C-D3 & 266.2 & 91.04 & 27 & 53 & 196.1 & 15 & 53 & 5.3 \\
\hline Cetirizine & Codeine-D6 & 389.2 & 166.1 & 39 & 54 & 201 & 17 & 54 & 5.5 \\
\hline Chlorpheniramine & Codeine-D6 & 275.1 & 167 & 40 & 42 & 230.1 & 17 & 42 & 5.1 \\
\hline Cimetidine & Codeine-D6 & 253.2 & 117 & 16 & 48 & 159 & 15 & 48 & 3.2 \\
\hline Promethazine & Tramadol-13C-D3 & 285.1 & 198 & 25 & 41 & 86.11 & 16 & 41 & 5.4 \\
\hline \multicolumn{10}{|c|}{ Antihypertensives } \\
\hline Atenolol & Codeine-D6 & 267.2 & 190 & 18 & 63 & 145 & 26 & 63 & 3.2 \\
\hline Bezafibrate & Codeine-D6 & 362.1 & 139 & 25 & 59 & 316 & 13 & 59 & 5.8 \\
\hline Enalapril & Clindamycin-D3 & 349.2 & 303.1 & 16 & 57 & 206 & 17 & 57 & 4.9 \\
\hline Nifedipine & Tramadol-13C-D3 & 329.1 & 270.1 & 15 & 65 & 284.1 & 21 & 65 & 5.8 \\
\hline \multicolumn{10}{|c|}{ Antimycotics } \\
\hline Clotrimazole & Codeine-D6 & 277.1 & 241.1 & 26 & 73 & 165 & 22 & 73 & 5.6 \\
\hline Fluconazole & Fluconazole-D4 & 307.1 & 238 & 15 & 57 & 220 & 18 & 57 & 5 \\
\hline \multicolumn{10}{|c|}{ Antiparasitics } \\
\hline Albendazole & Codeine-D6 & 266.1 & 191 & 33 & 67 & 234 & 19 & 67 & 5.4 \\
\hline
\end{tabular}


Table A3 continued. MS/MS transitions, collision energies, tube lenses, associated internal standards, and retention times for all analytes

\begin{tabular}{|c|c|c|c|c|c|c|c|c|c|}
\hline Compound & Internal standard & $\begin{array}{c}\text { Precursor } \\
(\mathrm{m} / \mathrm{z})\end{array}$ & $\begin{array}{c}\text { Product } \\
\text { ion }(\mathrm{m} / \mathrm{z}) 1\end{array}$ & $\begin{array}{c}\text { Collision } \\
\text { energy }(V) 1\end{array}$ & $\begin{array}{l}\text { RF Lens } \\
\text { (V) } 1\end{array}$ & $\begin{array}{c}\text { Product } \\
\text { ion } \mathrm{m} / \mathrm{z}) 2 \\
\end{array}$ & $\begin{array}{c}\text { Collision } \\
\text { energy (V) } 2\end{array}$ & $\begin{array}{l}\text { RF Lens } \\
\text { (V) } 2\end{array}$ & $\begin{array}{l}\text { Retention } \\
\text { time (min) }\end{array}$ \\
\hline \multicolumn{10}{|c|}{ Antiretrovirals } \\
\hline Abacavir & Codeine-D6 & 287.2 & 150 & 30 & 64 & 191 & 19 & 64 & 4.4 \\
\hline Atazanavir & Atazanavir-D5 & 705.2 & 534.3 & 26 & 110 & 335.2 & 27 & 110 & 5.6 \\
\hline Darunavir & Darunavir-D9 & 548.2 & 436.2 & 10 & 62 & 392.2 & 12 & 62 & 5.8 \\
\hline Etravirine & Tramadol-13C-D3 & 437.1 & 273 & 29 & 150 & 306 & 38 & 150 & 6.2 \\
\hline Lamivudine & Trimethoprim-13C-D3 & 230 & 94.99 & 35 & 31 & 112.1 & 11 & 31 & 2.9 \\
\hline Nevirapine & Oxazepam-D5 & 267.1 & 198.1 & 36 & 82 & 226.1 & 25 & 82 & 5.1 \\
\hline Raltegravir & Ketoprofen-D3 & 445.2 & 109.1 & 31 & 73 & 361.1 & 17 & 73 & 5.6 \\
\hline Saquinavir & Codeine-D6 & 671.2 & 433.2 & 30 & 110 & 570.3 & 30 & 110 & 5.6 \\
\hline \multicolumn{10}{|c|}{ Antivirals } \\
\hline Aciclovir & Codeine-D6 & 226.1 & 135.1 & 28 & 31 & 152.1 & 12 & 31 & 2.8 \\
\hline Famciclovir & Codeine-D6 & 322.2 & 280.1 & 17 & 87 & 136.1 & 27 & 87 & 4.7 \\
\hline \multicolumn{10}{|c|}{ Decongestants } \\
\hline Oxymetazoline & Tramadol-13C-D3 & 261.2 & 135.1 & 34 & 75 & 205.1 & 24 & 75 & 5.3 \\
\hline \multicolumn{10}{|c|}{ Herbicides/pesticides } \\
\hline Atrazine & Codeine-D6 & 216.1 & 132 & 23 & 49 & 174.1 & 17 & 49 & 5.7 \\
\hline Tebuthiuron & Tramadol-13C-D3 & 229.1 & 116 & 27 & 55 & 172.1 & 17 & 55 & 5.3 \\
\hline Terbuthylazine & Tramadol-13C-D3 & 230.1 & 167 & 33 & 61 & 174.1 & 17 & 61 & 6 \\
\hline \multicolumn{10}{|c|}{ Hormonal contraceptives } \\
\hline Levonorgestrel & Ketoprofen-D3 & 313.2 & 185.1 & 19 & 57 & 245.1 & 17 & 57 & 6.1 \\
\hline Medroxyprogesterone & Tramadol-13C-D3 & 345.2 & 327.2 & 15 & 63 & 123 & 24 & 63 & 6.1 \\
\hline Norgestrel & Codeine-D6 & 313.2 & 295.2 & 14 & 59 & 245.2 & 17 & 59 & 6.1 \\
\hline Progesterone & Tramadol-13C-D3 & 315.2 & 97.04 & 21 & 63 & 109 & 25 & 63 & 6.4 \\
\hline \multicolumn{10}{|c|}{ Psycholeptics/antidepressants } \\
\hline Amitriptyline & Tramadol-13C-D3 & 278.2 & 191.1 & 26 & 100 & 233 & 18 & 100 & 5.5 \\
\hline Clozapine & Tramadol-13C-D3 & 327.1 & 192.1 & 43 & 75 & 270 & 22 & 75 & 5.1 \\
\hline Diazepam & Codeine-D6 & 285.1 & 154.1 & 26 & 76 & 193.1 & 31 & 76 & 5.9 \\
\hline Fluoxetine & Tramadol-13C-D3 & 310.1 & 148.1 & 10 & 41 & 44.22 & 10 & 41 & 5.5 \\
\hline Haloperidol & Tramadol-13C-D3 & 376.1 & 123 & 39 & 130 & 165 & 24 & 130 & 5.4 \\
\hline Lorazepam & Tramadol-13C-D3 & 321 & 303 & 14 & 67 & 275.1 & 21 & 67 & 5.6 \\
\hline Oxazepam & Oxazepam-D5 & 287 & 269 & 13 & 66 & 241 & 22 & 66 & 5.6 \\
\hline \multicolumn{10}{|c|}{ Stimulants } \\
\hline Caffeine & Codeine-D6 & 195.1 & 110 & 23 & 63 & 138.1 & 18 & 63 & 4.5 \\
\hline \multicolumn{10}{|c|}{ Internal standards } \\
\hline Atazanavir-D5 & & 710.2 & 340.2 & 29 & 120 & 539.3 & 27 & 120 & 5.6 \\
\hline Carbamazepine-D10 & & 247.1 & 204.1 & 21 & 69 & 202.1 & 34 & 69 & 5.5 \\
\hline Clindamycin-D3 & & 428.2 & 129.2 & 27 & 86 & 380.2 & 19 & 86 & 5.1 \\
\hline Codeine-D6 & & 306.2 & 218.1 & 26 & 81 & 165.1 & 40 & 81 & 3.9 \\
\hline Darunavir-D9 & & 557.2 & 401.2 & 13 & 65 & 445.2 & 10 & 65 & 5.8 \\
\hline Fluconazole-D4 & & 311.1 & 223 & 18 & 63 & 242.1 & 16 & 63 & 5 \\
\hline Ketoprofen-D3 & & 258.1 & 212.1 & 14 & 57 & 105 & 23 & 57 & 5.8 \\
\hline Oxazepam-D5 & & 292.1 & 246.1 & 23 & 66 & 274 & 14 & 66 & 5.6 \\
\hline Sulfamethoxazole-D4 & & 258.1 & 160 & 16 & 54 & 112 & 25 & 54 & 5.3 \\
\hline Tramadol-13C-D3 & & 268.2 & 58.1 & 18 & 46 & 250.1 & 10 & 46 & 5 \\
\hline Trimethoprim-13C-D3 & & 295.1 & 230.1 & 23 & 79 & 123.1 & 25 & 79 & 4.7 \\
\hline
\end{tabular}

Table A4. Temperature, reaction time, yield, surface area and pore volume of the biochars

\begin{tabular}{|c|c|c|c|c|c|}
\hline \multirow[t]{2}{*}{ Feedstock } & CT & RT & Yield & CSA & PV \\
\hline & $\left({ }^{\circ} \mathrm{C}\right)$ & (h) & $(\%)$ & $\left(\mathrm{m}^{2} / \mathrm{g}\right)$ & $\left(\mathrm{cm}^{3} / \mathrm{g}\right)$ \\
\hline Olive residues & 260 & 3 & 56 & 0.1 & 0.02 \\
\hline Tomato residues & 260 & 3 & 50 & 0.6 & 0.05 \\
\hline Rice husks & 260 & 3 & 59 & 3.6 & 0.07 \\
\hline African palm tree & 260 & 3 & 60 & 0.5 & 0.07 \\
\hline
\end{tabular}

$C T$-combustion temperature; $R T$ - reaction time, yield; CSA - char surface area; $P V$ - pore volume

After the carbonization process the yield of the chars were calculated with the equation:

Yield $(\%)=\left(m / m_{\text {biomass }}\right) \times 100$

where ' $m$ ' is the dry mass of the char and ' $m_{\text {biomass }}$ is the initial dry mass of the biomass before the carbonization. The dry mass of the biomass was analysed by placing samples of biochar in an oven at $105^{\circ} \mathrm{C}$, when the sample weight was stable the dry weight was obtained. Surface area and pore volume were determined using Nitrogen adsorption and are presented in Table A4. This analysis was performed with a TriStar 3000 . Prior to analysis the chars were degassed, with a micromeritics SmartPrep degasser, at $120^{\circ} \mathrm{C}$ with N2 (g) for approximately $2 \mathrm{~h}$. Subsequently, the chars were cooled to 77K with $\mathrm{N} 2 \mathrm{(I}$ ) and the surface area was determined under vacuum. 
Table A5. Atomic concentration of carbon functional groups in percentage for the C1s spectra from the XPS analysis. Five distinct functional groups are derived from the binding energy measured in $\mathrm{eV}$

\begin{tabular}{|c|c|c|c|c|c|}
\hline \multirow[t]{2}{*}{ Feedstock } & C-C sp2 & C-C line & $\mathrm{C}-\mathrm{OH}$ & $\mathrm{C}=\mathrm{O}$ & $\mathrm{COOH}$ \\
\hline & $(\%)$ & $(\%)$ & (\%) & $(\%)$ & (\%) \\
\hline Olive residues & 71 & 9 & 6 & - & 4 \\
\hline Tomato residues & 66 & 14 & 2 & - & 3 \\
\hline Rice husks & 53 & - & 12 & 3 & 4 \\
\hline African palm tree & 59 & 10 & 7 & 3 & 5 \\
\hline
\end{tabular}

TC-C sp2 (286.4 eV), C-C line (285.3 - 285.9 eV), C-OH (285.9-286.6 eV), C=O (287.0 - 287.9 eV) and COOH (288.3-289.2 eV)

The surface functionalities of the biochars was analysed using X-ray photoelectron spectroscopy (XPS), to obtain both qualitative and quantitative data for all elements, except for $\mathrm{H}$ and $\mathrm{He}$. It also provides specific information about functional groups present in the top surface layer (3-5 $\mathrm{nm}$ ). The XPS analysis was performed using an AXIS Ultra DLD with the lens in hybrid mode, pass energy 160 was used for the resolution, and an acquisition time of 330 seconds was applied. Five sweeps were performed with a dwell time of 60 ms. The charge nebuliser was on.

Table A6. Linearity (R2), limit of quantification (LOQ, in pg on column), and filter recovery

\begin{tabular}{|c|c|c|c|c|c|c|c|c|c|}
\hline \multirow[b]{2}{*}{ Compound } & \multicolumn{3}{|c|}{ Linearity } & \multicolumn{3}{|c|}{ LOQ } & \multicolumn{3}{|c|}{ Filter recovery } \\
\hline & $\mathrm{mq}$ & eff & inf & $\mathrm{mq}$ & eff & inf & MQ & eff & inf \\
\hline \multicolumn{10}{|c|}{ Analgesics/anti-inflammatory drugs } \\
\hline Betamethasone & 0.9985 & 0.9987 & 0.9979 & 20 & 80 & 300 & 130 & 110 & 140 \\
\hline Betamethasone-17, 21-dipropionate & 0.9955 & 0.9964 & 0.998 & 50 & 100 & 400 & 16 & 25 & 21 \\
\hline Betamethasone-17-valerate & 0.9983 & 0.9988 & 0.998 & 60 & 200 & 100 & 36 & 45 & 41 \\
\hline Budesonide & 0.9987 & 0.9983 & 0.9982 & 40 & 300 & 500 & 52 & 45 & 120 \\
\hline Codeine & 0.9994 & 0.9992 & 0.9991 & 10 & 100 & 200 & 120 & 90 & 100 \\
\hline Diclofenac & 0.9988 & 0.9976 & 0.9987 & 40 & 60 & 90 & 51 & 80 & 82 \\
\hline Ketoprofen & 0.9988 & 0.9976 & 0.9952 & 20 & 200 & 300 & 110 & 75 & 96 \\
\hline Paracetamol & 0.9999 & 0.9973 & 0.9975 & 30 & 10 & 200 & 150 & 96 & 110 \\
\hline Tramadol & 0.9914 & 0.9978 & 0.9973 & 20 & 300 & 100 & 110 & 94 & 100 \\
\hline \multicolumn{10}{|c|}{ Antiarrhythmics } \\
\hline Carvedilol & 0.9991 & 0.9976 & 0.9996 & 30 & 100 & 200 & 0 & 0 & 0 \\
\hline Lignocaane & 0.9995 & 0.9992 & 0.9972 & 7 & 100 & 60 & 140 & 99 & 130 \\
\hline \multicolumn{10}{|c|}{ Antibiotics } \\
\hline Amoxicillin & 0.9986 & 0.9983 & 0.9947 & 20 & 100 & 40 & 210 & 110 & 180 \\
\hline Ciprofloxacin & 0.9979 & 0.9971 & 0.9955 & 9 & 200 & 200 & 77 & 110 & 67 \\
\hline Clindamycin & 0.9991 & 0.9989 & 0.9993 & 10 & 100 & 40 & 120 & 100 & 130 \\
\hline Erythromycin & 0.9987 & 0.9984 & 0.9986 & 10 & 90 & 40 & 78 & 100 & 100 \\
\hline Flucloxacillin & 0.9968 & 0.9987 & 0.9972 & 10 & 100 & 100 & 98 & 110 & 120 \\
\hline Levofloxacin & 0.9994 & 0.9993 & 0.9955 & 8 & 10 & 20 & 90 & 85 & 60 \\
\hline Linezolid & 0.9984 & 0.9993 & 0.9994 & 8 & 30 & 100 & 85 & 98 & 140 \\
\hline Nalidixic acid & 0.9994 & 0.9938 & 0.9982 & 10 & 60 & 40 & 140 & 90 & 130 \\
\hline Sulfamethazine & 0.9961 & 0.9924 & 0.9984 & 30 & 50 & 20 & 150 & 110 & 140 \\
\hline Sulfamethoxazole & 0.9988 & 0.9969 & 0.9987 & 6 & 200 & 300 & 110 & 100 & 130 \\
\hline Trimethoprim & 0.9994 & 0.999 & 0.9992 & 4 & 20 & 50 & 120 & 100 & 110 \\
\hline Virginiamycin & 0.9952 & 0.999 & 0.9942 & 200 & 100 & 200 & 110 & 100 & 130 \\
\hline \multicolumn{10}{|c|}{ Anticholinergics } \\
\hline Atropine & 0.9989 & 0.9989 & 0.9984 & 8 & 10 & 8 & 170 & 98 & 150 \\
\hline Biperiden & 0.9984 & 0.999 & 0.9993 & 4 & 10 & 7 & 87 & 100 & 120 \\
\hline Orphenadrine & 0.999 & 0.9989 & 0.999 & 8 & 5 & 10 & 94 & 98 & 110 \\
\hline \multicolumn{10}{|c|}{ Anticonvulsants } \\
\hline Acetazolamide & 0.9983 & 0.9988 & 0.9979 & 7 & 300 & 700 & 170 & 100 & 99 \\
\hline Carbamazepine & 0.9993 & 0.9984 & 0.9996 & 10 & 200 & 60 & 110 & 110 & 110 \\
\hline Lamotrigine & 0.999 & 0.9974 & 0.9978 & 10 & 500 & 200 & 170 & 110 & 100 \\
\hline Phenytoin & 0.9978 & 0.9963 & 0.9966 & 50 & 200 & 600 & 94 & 100 & 120 \\
\hline \multicolumn{10}{|c|}{ Antidiabetics } \\
\hline Glibenclamide & 0.993 & 0.9988 & 0.9979 & 40 & 100 & 200 & 0 & 51 & 79 \\
\hline Gliclazide & 0.999 & 0.9977 & 0.9982 & 9 & 20 & 10 & 90 & 100 & 120 \\
\hline
\end{tabular}


Table A6 continued. Linearity (R2), limit of quantification (LOQ, in pg on column), and filter recovery

\begin{tabular}{|c|c|c|c|c|c|c|c|c|c|}
\hline \multirow[b]{2}{*}{ Compound } & \multicolumn{3}{|c|}{ Linearity } & \multicolumn{3}{|c|}{ LOQ } & \multicolumn{3}{|c|}{ Filter recovery } \\
\hline & $\mathrm{mq}$ & eff & inf & $\mathrm{mq}$ & eff & inf & MQ & eff & inf \\
\hline \multicolumn{10}{|c|}{ Antidotes } \\
\hline Naloxone & 0.9983 & 0.9987 & 0.9988 & 10 & 30 & 300 & 92 & 110 & 130 \\
\hline \multicolumn{10}{|c|}{ Antihistamines } \\
\hline Antazoline & 0.9963 & 0.9985 & 0.9975 & 4 & 20 & 20 & 97 & 100 & 110 \\
\hline Cetirizine & 0.9992 & 0.9972 & 0.9987 & 30 & 100 & 300 & 120 & 97 & 110 \\
\hline Chlorpheniramine & 0.9979 & 0.9965 & 0.998 & 30 & 10 & 10 & 110 & 93 & 130 \\
\hline Cimetidine & 0.9973 & 0.9986 & 0.9988 & 20 & 10 & 20 & 140 & 110 & 140 \\
\hline Promethazine & 0.9982 & 0.9984 & 0.9934 & 20 & 4 & 20 & 62 & 85 & 80 \\
\hline \multicolumn{10}{|c|}{ Antihypertensives } \\
\hline Atenolol & 0.9977 & 0.9981 & 0.9976 & 3 & 200 & 200 & 150 & 97 & 100 \\
\hline Bezafibrate & 0.9992 & 0.9989 & 0.9982 & 20 & 200 & 200 & 90 & 81 & 97 \\
\hline Enalapril & 0.9989 & 0.9982 & 0.9987 & 9 & 30 & 200 & 140 & 110 & 110 \\
\hline Nifedipine & 0.9988 & 0.9994 & 0.9979 & 20 & 6 & 40 & 61 & 83 & 72 \\
\hline \multicolumn{10}{|c|}{ Antimycotics } \\
\hline Clotrimazole & 0.9966 & 0.9987 & 0.9982 & 3 & 90 & 100 & 42 & 2.8 & 11 \\
\hline Fluconazole & 0.9993 & 0.9986 & 0.9996 & 2 & 50 & 100 & 120 & 100 & 110 \\
\hline \multicolumn{10}{|c|}{ Antiparasitics } \\
\hline Albendazole & 0.9988 & 0.9984 & 0.9965 & 20 & 10 & 20 & 91 & 49 & 65 \\
\hline \multicolumn{10}{|c|}{ Antiretrovirals } \\
\hline Abacavir & 0.9952 & 0.9978 & 0.9989 & 10 & 9 & 20 & 140 & 100 & 140 \\
\hline Atazanavir & 0.9993 & 0.9977 & 0.9981 & 30 & 70 & 70 & 63 & 60 & 73 \\
\hline Darunavir & 0.9982 & 0.9931 & 0.9976 & 40 & 300 & 400 & 77 & 57 & 80 \\
\hline Etravirine & 0.9992 & 0.9993 & 0.9978 & 20 & 70 & 200 & 0.53 & 0 & 10 \\
\hline Lamivudine & 0.9997 & 0.9992 & 0.9987 & 5 & 60 & 50 & 95 & 120 & 130 \\
\hline Nevirapine & 0.999 & 0.9981 & 0.998 & 3 & 20 & 10 & 100 & 100 & 140 \\
\hline Raltegravir & 0.9979 & 0.9987 & 0.9964 & 10 & 50 & 200 & 130 & 97 & 100 \\
\hline Saquinavir & 0.9977 & 0.9984 & 0.9995 & 20 & 40 & 60 & 18 & 7.7 & 14 \\
\hline \multicolumn{10}{|c|}{ Antivirals } \\
\hline Aciclovir & 0.9998 & 0.9984 & 0.9972 & 4 & 300 & 700 & 180 & 92 & 110 \\
\hline Famciclovir & 0.9988 & 0.9993 & 0.9971 & 2 & 10 & 9 & 180 & 100 & 150 \\
\hline \multicolumn{10}{|c|}{ Decongestants } \\
\hline Oxymetazoline & 0.9992 & 0.9993 & 0.9987 & 6 & 20 & 8 & 110 & 100 & 120 \\
\hline \multicolumn{10}{|c|}{ Herbicides/pesticides } \\
\hline Atrazine & 0.9973 & 0.9974 & 0.9983 & 3 & 8 & 20 & 150 & 110 & 130 \\
\hline Tebuthiuron & 0.9987 & 0.9984 & 0.9984 & 5 & 10 & 30 & 120 & 110 & 120 \\
\hline Terbuthylazine & 0.9972 & 0.9986 & 0.9981 & 3 & 7 & 20 & 100 & 87 & 110 \\
\hline \multicolumn{10}{|c|}{ Hormonal contraceptives } \\
\hline Levonorgestrel & 0.9982 & 0.9983 & 0.9956 & 100 & 200 & 300 & 80 & 63 & 70 \\
\hline Medroxyprogesterone & 0.995 & 0.999 & 0.9975 & 20 & 100 & 100 & 67 & 67 & 77 \\
\hline Norgestrel & 0.9984 & 0.9954 & 0.997 & 40 & 300 & 1000 & 73 & 110 & 150 \\
\hline Progesterone & 0.9951 & 0.9956 & 0.9965 & 30 & 200 & 100 & 44 & 35 & 37 \\
\hline \multicolumn{10}{|c|}{ Psycholeptics/antidepressants } \\
\hline Amitriptyline & 0.9986 & 0.9991 & 0.9987 & 8 & 40 & 100 & 52 & 80 & 76 \\
\hline Clozapine & 0.9988 & 0.9996 & 0.9995 & 50 & 50 & 20 & 48 & 68 & 84 \\
\hline Diazepam & 0.9995 & 0.9981 & 0.9958 & 6 & 20 & 40 & 83 & 79 & 130 \\
\hline Fluoxetine & 0.9983 & 0.9983 & 0.9985 & 20 & 30 & 30 & 32 & 69 & 74 \\
\hline Haloperidol & 0.9992 & 0.999 & 0.9993 & 10 & 20 & 30 & 48 & 80 & 57 \\
\hline Lorazepam & 0.9973 & 0.9983 & 0.9981 & 5 & 200 & 90 & 110 & 93 & 100 \\
\hline Oxazepam & 0.9995 & 0.9995 & 0.9996 & 9 & 200 & 200 & 100 & 100 & 100 \\
\hline \multicolumn{10}{|c|}{ Stimulants } \\
\hline Caffeine & 0.9989 & 0.9986 & 0.9978 & 9 & 30 & 800 & 140 & 100 & 81 \\
\hline
\end{tabular}


Table A7. Method (1), intraday (2), and interday (3) precision and accuracy

\begin{tabular}{|c|c|c|c|c|c|c|c|c|c|c|c|c|c|c|c|c|c|c|}
\hline \multirow[b]{3}{*}{ Compound } & \multicolumn{9}{|c|}{ Precision } & \multicolumn{9}{|c|}{ Accuracy } \\
\hline & \multicolumn{3}{|c|}{$\mathrm{mq}$} & \multicolumn{3}{|c|}{ eff } & \multicolumn{3}{|c|}{ inf } & \multicolumn{3}{|c|}{$\mathrm{mq}$} & \multicolumn{3}{|c|}{ eff } & \multicolumn{3}{|c|}{ inf } \\
\hline & 1 & 2 & 3 & 1 & 2 & 3 & 1 & 2 & 3 & 1 & 2 & 3 & 1 & 2 & 3 & 1 & 2 & 3 \\
\hline \multicolumn{19}{|c|}{ Analgesics/anti-inflammatory drugs } \\
\hline Betamethasone & 1.3 & 4.5 & 4.8 & 3.1 & 5.4 & 7.4 & 6.9 & 6.7 & 7.7 & 110 & 110 & 89 & 94 & 94 & 89 & 90 & 96 & 99 \\
\hline Betamethasone-17,21-dipropionate & 6.8 & 5.7 & 5.1 & 13 & 8.7 & 10 & 16 & 14 & 11 & 140 & 140 & 110 & 140 & 140 & 140 & 130 & 140 & 150 \\
\hline Betamethasone-17-valerate & 8.1 & 6.1 & 4.9 & 2.7 & 7.2 & 7.8 & 10 & 7.7 & 6.9 & 85 & 88 & 80 & 94 & 92 & 90 & 89 & 97 & 110 \\
\hline Budesonide & 5.1 & 4.9 & 7.1 & 10 & 9.2 & 13 & 15 & 11 & 9.8 & 82 & 81 & 73 & 85 & 85 & 88 & 84 & 83 & 99 \\
\hline Codeine & 3.1 & 2 & 2.4 & 0.92 & 5.4 & 5.1 & 1.3 & 5.1 & 4.7 & 97 & 97 & 89 & 110 & 100 & 98 & 110 & 120 & 110 \\
\hline Diclofenac & 7 & 6.5 & 6.2 & 14 & 11 & 8.6 & 0.43 & 5.4 & 10 & 110 & 100 & 97 & 86 & 82 & 78 & 110 & 120 & 93 \\
\hline Ketoprofen & 3.8 & 3.4 & 3.7 & 11 & 11 & 8.9 & 6.3 & 6.7 & 8 & 110 & 110 & 96 & 95 & 100 & 99 & 110 & 110 & 96 \\
\hline Paracetamol & 2.2 & 1.4 & 1.9 & 2 & 3.5 & 3.8 & 7.1 & 5.5 & 5.7 & 100 & 100 & 91 & 120 & 120 & 110 & 110 & 110 & 97 \\
\hline Tramadol & 3.8 & 2.9 & 3.9 & 2.8 & 1.8 & 7.4 & 2.3 & 5.1 & 6.1 & 85 & 86 & 120 & 87 & 86 & 82 & 58 & 62 & 72 \\
\hline \multicolumn{19}{|c|}{ Antiarrhythmics } \\
\hline Carvedilol & 6 & 4 & 4.6 & 3 & 3.7 & 5 & 9.9 & 9.1 & 9.4 & 89 & 88 & 72 & 77 & 77 & 77 & 67 & 73 & 84 \\
\hline Lignocaine & 1.8 & 2.2 & 2.9 & 3.5 & 4.6 & 6.4 & 2.4 & 3.7 & 4.3 & 98 & 96 & 90 & 89 & 89 & 91 & 84 & 92 & 88 \\
\hline \multicolumn{19}{|c|}{ Antibiotics } \\
\hline Amoxicillin & 3.3 & 2.6 & 3.3 & 5.3 & 5.9 & 4.6 & 2.6 & 4.6 & 5 & 86 & 86 & 76 & 100 & 100 & 89 & 100 & 110 & 87 \\
\hline Ciprofloxacin & 4.2 & 3 & 3 & 4.8 & 4.9 & 3.8 & 6.9 & 7.8 & 7.3 & 88 & 89 & 78 & 83 & 83 & 89 & 66 & 72 & 74 \\
\hline Clindamycin & 0.56 & 0.98 & 1.7 & 3.3 & 3.1 & 2.1 & 2.3 & 2.1 & 2.4 & 110 & 110 & 100 & 110 & 110 & 100 & 110 & 110 & 100 \\
\hline Erythromycin & 4.4 & 4.1 & 4.5 & 4.5 & 5.9 & 10 & 12 & 6.5 & 7.4 & 90 & 87 & 73 & 63 & 64 & 60 & 58 & 62 & 62 \\
\hline Flucloxacillin & 7.4 & 4.2 & 5 & 2.4 & 4.3 & 6.8 & 9.2 & 7 & 7 & 71 & 70 & 66 & 95 & 94 & 91 & 97 & 100 & 110 \\
\hline Levofloxacin & 3.3 & 2.8 & 3.1 & 5.9 & 4.9 & 6.6 & 4.9 & 6.1 & 6 & 110 & 110 & 92 & 95 & 95 & 90 & 100 & 110 & 90 \\
\hline Linezolid & 1.3 & 0.98 & 1.9 & 1 & 1.2 & 3.2 & 7.7 & 4.7 & 4.2 & 91 & 90 & 86 & 110 & 110 & 100 & 80 & 84 & 77 \\
\hline Nalidixic acid & 3.6 & 4.1 & 3.4 & 8.4 & 6 & 7 & 6.9 & 4.3 & 4.9 & 110 & 110 & 110 & 110 & 110 & 110 & 99 & 100 & 100 \\
\hline Sulfamethazine & 4.6 & 4.6 & 6.5 & 11 & 15 & 15 & 8.6 & 9.7 & 11 & 110 & 110 & 110 & 86 & 95 & 97 & 110 & 120 & 98 \\
\hline Sulfamethoxazole & 2.6 & 2.9 & 3.7 & 18 & 12 & 12 & 6 & 6.5 & 5.7 & 110 & 110 & 98 & 100 & 100 & 95 & 100 & 110 & 110 \\
\hline Trimethoprim & 2.9 & 3.4 & 3.7 & 5.8 & 3.4 & 3.2 & 5.6 & 4.2 & 3.7 & 100 & 100 & 98 & 120 & 120 & 110 & 120 & 120 & 110 \\
\hline Virginiamycin & 1.6 & 3.6 & 6.3 & 15 & 11 & 11 & 9 & 7.4 & 6.5 & 140 & 140 & 130 & 120 & 120 & 110 & 90 & 97 & 90 \\
\hline \multicolumn{19}{|c|}{ Anticholinergics } \\
\hline Atropine & 5 & 4.2 & 3.2 & 3.2 & 3.4 & 3.2 & 1.2 & 2.7 & 2.7 & 97 & 96 & 89 & 110 & 110 & 110 & 120 & 120 & 110 \\
\hline Biperiden & 1.7 & 1.7 & 2.8 & 0.32 & 3.3 & 5.1 & 3.7 & 1.7 & 3.6 & 120 & 120 & 110 & 75 & 77 & 69 & 73 & 75 & 72 \\
\hline Orphenadrine & 2.4 & 2.1 & 2.5 & 2.7 & 3.7 & 6 & 3.3 & 2.4 & 3.4 & 110 & 110 & 96 & 96 & 98 & 89 & 94 & 97 & 91 \\
\hline \multicolumn{19}{|c|}{ Anticonvulsants } \\
\hline Acetazolamide & 5 & 2.9 & 2 & 1.9 & 4.2 & 4 & 2 & 5.5 & 4.2 & 83 & 81 & 72 & 74 & 72 & 69 & 63 & 68 & 61 \\
\hline Carbamazepine & 1 & 2 & 2 & 5 & 4.2 & 4.1 & 2.7 & 2.7 & 2.8 & 120 & 120 & 110 & 110 & 110 & 110 & 110 & 110 & 100 \\
\hline Lamotrigine & 3.6 & 3.9 & 4.1 & 1.7 & 4 & 7 & 7.2 & 7.5 & 8.7 & 91 & 87 & 74 & 89 & 88 & 93 & 100 & 100 & 95 \\
\hline Phenytoin & 4.5 & 7.6 & 7.2 & 3.7 & 3.3 & 8.4 & 12 & 9.6 & 10 & 83 & 79 & 68 & 63 & 62 & 65 & 66 & 69 & 72 \\
\hline \multicolumn{19}{|c|}{ Antidiabetics } \\
\hline Glibenclamide & 5.2 & 5.1 & 3.6 & 12 & 6 & 5.8 & 6.4 & 5 & 5.5 & 110 & 110 & 110 & 83 & 80 & 86 & 78 & 84 & 89 \\
\hline Gliclazide & 2.7 & 2.7 & 2.9 & 3.8 & 4.9 & 6.9 & 5.2 & 2.6 & 3.5 & 93 & 91 & 85 & 120 & 120 & 110 & 100 & 110 & 120 \\
\hline & & & & & & Anti & dotes & & & & & & & & & & & \\
\hline Naloxone & 3 & 2.5 & 2.6 & 6.4 & 4.8 & 4.5 & 1.4 & 4.2 & 5 & 120 & 120 & 120 & 120 & 120 & 110 & 120 & 130 & 110 \\
\hline & & & & & & ItIn & tamin & & & & & & & & & & & \\
\hline Antazoline & 0.13 & 1.7 & 2.1 & 2.5 & 2 & 3.4 & 3.9 & 3.5 & 3.7 & 120 & 120 & 110 & 120 & 120 & 110 & 110 & 110 & 110 \\
\hline Cetirizine & 3.1 & 2.5 & 3.7 & 5.1 & 7.2 & 9.8 & 6.6 & 8.4 & 7.8 & 100 & 100 & 85 & 130 & 140 & 120 & 98 & 100 & 110 \\
\hline Chlorpheniramine & 4.1 & 1.9 & 2.6 & 4.1 & 2.7 & 3.7 & 6.1 & 4.9 & 4.7 & 82 & 79 & 100 & 77 & 78 & 110 & 68 & 71 & 96 \\
\hline Cimetidine & 1.9 & 2.7 & 1.8 & 1.9 & 2.7 & 3.8 & 3.5 & 3.2 & 3.8 & 130 & 130 & 110 & 120 & 120 & 110 & 120 & 130 & 110 \\
\hline Promethazine & 2 & 3.1 & 3.1 & 5.4 & 5.8 & 7.7 & 7.9 & 5.2 & 4.9 & 120 & 120 & 110 & 66 & 66 & 64 & 60 & 66 & 62 \\
\hline
\end{tabular}


Table A7 continued. Method (1), intraday (2), and interday (3) precision and accuracy

\begin{tabular}{|c|c|c|c|c|c|c|c|c|c|c|c|c|c|c|c|c|c|c|}
\hline \multirow[b]{3}{*}{ Compound } & \multicolumn{9}{|c|}{ Precision } & \multicolumn{9}{|c|}{ Accuracy } \\
\hline & \multicolumn{3}{|c|}{$\mathrm{mq}$} & \multicolumn{3}{|c|}{ eff } & \multicolumn{3}{|c|}{$\inf$} & \multicolumn{3}{|c|}{$\mathrm{mq}$} & \multicolumn{3}{|c|}{ eff } & \multicolumn{3}{|c|}{ inf } \\
\hline & 1 & 2 & 3 & 1 & 2 & 3 & 1 & 2 & 3 & 1 & 2 & 3 & 1 & 2 & 3 & 1 & 2 & 3 \\
\hline \multicolumn{19}{|c|}{ Antihypertensives } \\
\hline Atenolol & 5.9 & 5.1 & 4.8 & 4.4 & 9.3 & 12 & 5 & 9.6 & 11 & 100 & 110 & 100 & 86 & 86 & 87 & 100 & 110 & 90 \\
\hline Bezafibrate & 1.6 & 5.1 & 4.9 & 9.1 & 7.8 & 10 & 3.8 & 4.8 & 6.5 & 94 & 94 & 99 & 100 & 97 & 90 & 96 & 96 & 94 \\
\hline Enalapril & 2.5 & 2.7 & 2.8 & 3.3 & 2.4 & 3.2 & 9.8 & 6.5 & 4.2 & 110 & 110 & 100 & 130 & 130 & 120 & 120 & 130 & 120 \\
\hline Nifedipine & 2 & 2.1 & 2.8 & 3.6 & 4.3 & 7.1 & 5.3 & 4.6 & 4.6 & 100 & 100 & 100 & 81 & 80 & 85 & 51 & 53 & 69 \\
\hline \multicolumn{19}{|c|}{ Antimycotics } \\
\hline Clotrimazole & 5.8 & 3.1 & 3.5 & 4.4 & 4.8 & 6.5 & 9.2 & 6 & 5.8 & 130 & 130 & 110 & 110 & 110 & 96 & 78 & 84 & 83 \\
\hline Fluconazole & 3 & 1.8 & 2.5 & 3 & 3.1 & 3 & 4.6 & 4.2 & 4 & 110 & 110 & 100 & 110 & 110 & 100 & 110 & 110 & 110 \\
\hline \multicolumn{19}{|c|}{ Antiparasitics } \\
\hline Albendazole & 1.7 & 2.5 & 3.1 & 6.1 & 7.9 & 6.3 & 5 & 6.1 & 6.2 & 110 & 110 & 97 & 120 & 120 & 110 & 120 & 120 & 99 \\
\hline \multicolumn{19}{|c|}{ Antiretrovirals } \\
\hline Abacavir & 1.6 & 1.3 & 2.2 & 5.1 & 4.2 & 3.4 & 4.3 & 3.7 & 4 & 140 & 140 & 120 & 130 & 130 & 120 & 110 & 120 & 100 \\
\hline Atazanavir & 8.6 & 4.2 & 6.2 & 5.1 & 6 & 7.2 & 6 & 7.1 & 5.5 & 110 & 110 & 91 & 110 & 110 & 92 & 110 & 110 & 96 \\
\hline Darunavir & 0.6 & 4 & 5.8 & 13 & 12 & 16 & 3.6 & 9.1 & 9.1 & 91 & 93 & 91 & 87 & 97 & 97 & 92 & 100 & 100 \\
\hline Etravirine & 1.4 & 3.4 & 3.9 & 3.5 & 5.4 & 6.5 & 8.4 & 11 & 8.4 & 91 & 92 & 71 & 99 & 100 & 97 & 97 & 100 & 96 \\
\hline Lamivudine & 2.4 & 3 & 3.6 & 2.6 & 5.1 & 4.2 & 7.8 & 4.4 & 4.5 & 100 & 110 & 100 & 81 & 81 & 70 & 110 & 120 & 100 \\
\hline Nevirapine & 1.6 & 2.3 & 4.3 & 4.1 & 3.5 & 6.1 & 1.6 & 2.5 & 3.3 & 120 & 120 & 110 & 110 & 110 & 99 & 90 & 95 & 79 \\
\hline Raltegravir & 0.64 & 2.1 & 3.5 & 7.6 & 7.7 & 7.2 & 7.4 & 8 & 7.5 & 120 & 120 & 110 & 100 & 110 & 110 & 84 & 88 & 82 \\
\hline Saquinavir & 5.8 & 4.7 & 3.8 & 7.7 & 5.4 & 6 & 5.5 & 7.1 & 6.7 & 88 & 86 & 72 & 77 & 76 & 76 & 67 & 74 & 85 \\
\hline \multicolumn{19}{|c|}{ Antivirals } \\
\hline Aciclovir & 1.8 & 2.3 & 2.1 & 9 & 7.8 & 5.9 & 6.1 & 7.1 & 6.2 & 110 & 110 & 96 & 86 & 86 & 82 & 97 & 110 & 92 \\
\hline Famciclovir & 3.1 & 3.4 & 3.3 & 2.5 & 3.6 & 6.4 & 0.96 & 3.8 & 5.1 & 100 & 110 & 110 & 110 & 110 & 100 & 120 & 120 & 100 \\
\hline \multicolumn{19}{|c|}{ Decongestants } \\
\hline Oxymetazoline & 1.3 & 2.3 & 2.3 & 1.7 & 2.5 & 3.3 & 2.3 & 2.9 & 3.5 & 100 & 98 & 90 & 100 & 100 & 100 & 120 & 130 & 120 \\
\hline \multicolumn{19}{|c|}{ Herbicides/pesticides } \\
\hline Atrazine & 1.4 & 0.93 & 2.8 & 2.3 & 3.4 & 4.9 & 5 & 4.6 & 5 & 120 & 120 & 110 & 120 & 120 & 110 & 100 & 110 & 110 \\
\hline Tebuthiuron & 4.1 & 2.8 & 3 & 1.8 & 3.7 & 4.1 & 5.2 & 4.3 & 4.3 & 86 & 86 & 78 & 130 & 130 & 120 & 130 & 140 & 130 \\
\hline Terbuthylazine & 1.8 & 2.1 & 2.6 & 1.3 & 3.8 & 7.2 & 5.7 & 3.1 & 4.3 & 74 & 73 & 67 & 97 & 94 & 95 & 88 & 91 & 110 \\
\hline \multicolumn{19}{|c|}{ Hormonal contraceptives } \\
\hline Levonorgestrel & 6.9 & 5.7 & 8.3 & 17 & 13 & 12 & 13 & 13 & 10 & 85 & 87 & 80 & 95 & 99 & 92 & 86 & 89 & 90 \\
\hline Medroxyprogesterone & 4.1 & 5.7 & 5.4 & 3.6 & 4.9 & 6.3 & 3.4 & 4.8 & 7.1 & 69 & 67 & 61 & 84 & 84 & 81 & 90 & 91 & 100 \\
\hline Norgestrel & 1.1 & 6.3 & 5.4 & 7.5 & 6.4 & 8.4 & 6.7 & 11 & 8.7 & 88 & 83 & 74 & 130 & 140 & 130 & 110 & 120 & 140 \\
\hline Progesterone & 7.5 & 8.3 & 7.3 & 7.5 & 11 & 8.9 & 5.7 & 8 & 8.1 & 66 & 65 & 63 & 81 & 85 & 77 & 89 & 98 & 100 \\
\hline & & & & Psy & chol & tics & antid & ores & ants & & & & & & & & & \\
\hline Amitriptyline & 3.2 & 3.6 & 3.2 & 2.9 & 6.5 & 8.5 & 2.8 & 2.5 & 5.1 & 120 & 110 & 97 & 73 & 74 & 65 & 66 & 72 & 72 \\
\hline Clozapine & 3.7 & 4 & 2.7 & 2.6 & 3.1 & 3.9 & 4.2 & 2.8 & 2.6 & 120 & 120 & 110 & 99 & 100 & 100 & 110 & 120 & 110 \\
\hline Diazepam & 7.5 & 5.1 & 5.5 & 3.3 & 4.4 & 7.7 & 6.4 & 8.1 & 7.9 & 110 & 110 & 90 & 140 & 140 & 120 & 140 & 140 & 120 \\
\hline Fluoxetine & 3.5 & 3.3 & 3.6 & 5.5 & 6.4 & 9.3 & 5.5 & 3.2 & 5.5 & 81 & 81 & 65 & 64 & 64 & 56 & 59 & 62 & 61 \\
\hline Haloperidol & 2 & 2.3 & 2.8 & 1.7 & 4.5 & 8.2 & 7.1 & 3 & 5.4 & 99 & 97 & 82 & 74 & 77 & 68 & 70 & 73 & 74 \\
\hline Lorazepam & 3.1 & 2.7 & 3.5 & 4 & 5 & 7.2 & 3.4 & 4.5 & 4.9 & 80 & 79 & 72 & 110 & 120 & 110 & 110 & 120 & 130 \\
\hline Oxazepam & 1.7 & 1.7 & 2.4 & 0.71 & 2.4 & 3.4 & 5.2 & 2.4 & 4.7 & 110 & 110 & 100 & 110 & 110 & 110 & 110 & 110 & 100 \\
\hline & & & & & & StIn & lants & & & & & & & & & & & \\
\hline Caffeine & 2.1 & 1.8 & 2.5 & 2.4 & 2.6 & 3.1 & 6.3 & 6.4 & 12 & 87 & 85 & 76 & 130 & 120 & 110 & 120 & 120 & 110 \\
\hline
\end{tabular}


Table A8. Concentrations ( $\mathrm{ng} / \mathrm{L}$ ) of micropollutants in influent and effluent samples of the demonstration-scale decentralised wastewater treatment system in eThekwini

\begin{tabular}{|c|c|c|c|c|c|c|c|c|c|c|c|}
\hline \multirow[b]{3}{*}{ Compound } & \multicolumn{5}{|c|}{ Influent } & \multicolumn{6}{|c|}{ Effluent } \\
\hline & \multicolumn{2}{|c|}{ Day 1} & \multirow{2}{*}{$\begin{array}{l}\text { Day } 2 \\
07: 30\end{array}$} & \multicolumn{2}{|c|}{ Day 3} & \multicolumn{2}{|c|}{ Day 1} & \multicolumn{2}{|c|}{ Day 2} & \multicolumn{2}{|c|}{ Day 3} \\
\hline & 07:30 & $18: 00$ & & 07:30 & $18: 00$ & $07: 30$ & 18:00 & 07:30 & $18: 00$ & 07:30 & 18:00 \\
\hline \multicolumn{12}{|c|}{ Analgesics/anti-inflammatory drugs } \\
\hline Betamethasone & $<\mathrm{LOQ}$ & $<$ LOQ & $<$ LOQ & $<$ LOQ & $<\mathrm{LOQ}$ & $<\mathrm{LOQ}$ & $<$ LOQ & $<$ LOQ & $<\mathrm{LOQ}$ & $<\mathrm{LOQ}$ & $<\mathrm{LOQ}$ \\
\hline Betamethasone-17,21-dipropionate & $<\mathrm{LOQ}$ & $<$ LOQ & $<\mathrm{LOQ}$ & $<\mathrm{LOQ}$ & $<\mathrm{LOQ}$ & $<\mathrm{LOQ}$ & $<$ LOQ & $<$ LOQ & $<\mathrm{LOQ}$ & $<$ LOQ & $<$ LOQ \\
\hline Betamethasone-17-valerate & $<\mathrm{LOQ}$ & $<$ LOQ & $<$ LOQ & $<\mathrm{LOQ}$ & $<\mathrm{LOQ}$ & $<\mathrm{LOQ}$ & $<$ LOQ & $<\mathrm{LOQ}$ & $<\mathrm{LOQ}$ & $<$ LOQ & $<$ LOQ \\
\hline Budesonide & $<\mathrm{LOQ}$ & $<$ LOQ & $<$ LOQ & $<$ LOQ & $<\mathrm{LOQ}$ & $<$ LOQ & $<$ LOQ & $<$ LOQ & $<$ LOQ & $<$ LOQ & $<$ LOQ \\
\hline Codeine & $<\mathrm{LOQ}$ & $<\mathrm{LOQ}$ & $<$ LOQ & $<$ LOQ & $<\mathrm{LOQ}$ & $<$ LOQ & $<\mathrm{LOQ}$ & $<$ LOQ & $<$ LOQ & $<\mathrm{LOQ}$ & $<$ LOQ \\
\hline Diclofenac & 2100 & 2300 & 2400 & 2000 & 2800 & 1900 & 2300 & 2100 & 1900 & 2100 & 2100 \\
\hline Ketoprofen & $<\mathrm{LOQ}$ & $<\mathrm{LOQ}$ & $<\mathrm{LOQ}$ & $<L O Q$ & $<\mathrm{LOQ}$ & $<\mathrm{LOQ}$ & $<$ LOQ & $<\mathrm{LOQ}$ & $<\mathrm{LOQ}$ & $<\mathrm{LOQ}$ & $<$ LOQ \\
\hline Paracetamol & 150000 & 110000 & 120000 & 120000 & 180000 & 7400 & 4600 & 3600 & 2600 & 5900 & 3400 \\
\hline Tramadol & 520 & 300 & 310 & 290 & 220 & 430 & 430 & 390 & 390 & 360 & 390 \\
\hline \multicolumn{12}{|c|}{ Antiarrhythmics } \\
\hline Carvedilol & $<\mathrm{LOQ}$ & $<\mathrm{LOQ}$ & $<\mathrm{LOQ}$ & $<\mathrm{LOQ}$ & $<\mathrm{LOQ}$ & $<\mathrm{LOQ}$ & $<\mathrm{LOQ}$ & $<$ LOQ & $<\mathrm{LOQ}$ & $<\mathrm{LOQ}$ & $<$ LOQ \\
\hline Lignocaine & $<\mathrm{LOQ}$ & $<\mathrm{LOQ}$ & $<\mathrm{LOQ}$ & $<\mathrm{LOQ}$ & $<\mathrm{LOQ}$ & $<\mathrm{LOQ}$ & $<\mathrm{LOQ}$ & $<$ LOQ & $<$ LOQ & $<\mathrm{LOQ}$ & $<\mathrm{LOQ}$ \\
\hline \multicolumn{12}{|c|}{ Antibiotics } \\
\hline Amoxicillin & $<\mathrm{LOQ}$ & $<$ LOQ & $<$ LOQ & $<$ LOQ & $<\mathrm{LOQ}$ & $<\mathrm{LOQ}$ & $<\mathrm{LOQ}$ & $<\mathrm{LOQ}$ & $<\mathrm{LOQ}$ & $<$ LOQ & $<$ LOQ \\
\hline Ciprofloxacin & 1400 & 780 & 1300 & 1400 & 1800 & 1500 & 1500 & 1300 & 1800 & 1800 & 1500 \\
\hline Clindamycin & 760 & 230 & 120 & 150 & 110 & 230 & 250 & 230 & 290 & 290 & 300 \\
\hline Erythromycin & $<\mathrm{LOQ}$ & $<\mathrm{LOQ}$ & $<\mathrm{LOQ}$ & $<\mathrm{LOQ}$ & $<\mathrm{LOQ}$ & $<\mathrm{LOQ}$ & $<\mathrm{LOQ}$ & $<$ LOQ & $<\mathrm{LOQ}$ & $<\mathrm{LOQ}$ & $<$ LOQ \\
\hline Flucloxacillin & $<\mathrm{LOQ}$ & $<\mathrm{LOQ}$ & $<\mathrm{LOQ}$ & $<\mathrm{LOQ}$ & $<\mathrm{LOQ}$ & $<\mathrm{LOQ}$ & $<\mathrm{LOQ}$ & $<$ LOQ & $<\mathrm{LOQ}$ & $<\mathrm{LOQ}$ & $<\mathrm{LOQ}$ \\
\hline Levofloxacin & $<\mathrm{LOQ}$ & $<$ LOQ & 24 & 26 & 24 & 26 & 21 & 20 & 20 & 25 & 20 \\
\hline Linezolid & $<\mathrm{LOQ}$ & $<\mathrm{LOQ}$ & $<\mathrm{LOQ}$ & $<\mathrm{LOQ}$ & $<\mathrm{LOQ}$ & $<\mathrm{LOQ}$ & $<\mathrm{LOQ}$ & $<\mathrm{LOQ}$ & $<$ LOQ & $<\mathrm{LOQ}$ & $<\mathrm{LOQ}$ \\
\hline Nalidixic acid & $<\mathrm{LOQ}$ & $<\mathrm{LOQ}$ & $<\mathrm{LOQ}$ & $<\mathrm{LOQ}$ & $<\mathrm{LOQ}$ & $<\mathrm{LOQ}$ & $<\mathrm{LOQ}$ & $<\mathrm{LOQ}$ & $<\mathrm{LOQ}$ & $<\mathrm{LOQ}$ & $<\mathrm{LOQ}$ \\
\hline Sulfamethazine & $<\mathrm{LOQ}$ & $<\mathrm{LOQ}$ & $<$ LOQ & $<\mathrm{LOQ}$ & $<\mathrm{LOQ}$ & $<\mathrm{LOQ}$ & $<$ LOQ & $<\mathrm{LOQ}$ & $<\mathrm{LOQ}$ & $<\mathrm{LOQ}$ & $<$ LOQ \\
\hline Sulfamethoxazole & 9300 & 7000 & 14000 & 18000 & 11000 & 3200 & 2800 & 2000 & 2000 & 2400 & 2300 \\
\hline Trimethoprim & 1300 & 780 & 1400 & 2100 & 1300 & 300 & 330 & 250 & 250 & 260 & 340 \\
\hline Virginiamycin & $<\mathrm{LOQ}$ & $<\mathrm{LOQ}$ & $<$ LOQ & $<L O Q$ & $<\mathrm{LOQ}$ & $<\mathrm{LOQ}$ & $<$ LOQ & $<$ LOQ & $<\mathrm{LOQ}$ & $<\mathrm{LOQ}$ & $<$ LOQ \\
\hline \multicolumn{12}{|c|}{ Anticholinergics } \\
\hline Atropine & $<\mathrm{LOQ}$ & $<\mathrm{LOQ}$ & $<\mathrm{LOQ}$ & $<\mathrm{LOQ}$ & $<\mathrm{LOQ}$ & $<\mathrm{LOQ}$ & $<\mathrm{LOQ}$ & $<$ LOQ & $<\mathrm{LOQ}$ & $<\mathrm{LOQ}$ & $<$ LOQ \\
\hline Biperiden & $<\mathrm{LOQ}$ & $<\mathrm{LOQ}$ & $<\mathrm{LOQ}$ & $<\mathrm{LOQ}$ & $<\mathrm{LOQ}$ & $<\mathrm{LOQ}$ & $<\mathrm{LOQ}$ & $<\mathrm{LOQ}$ & $<\mathrm{LOQ}$ & $<\mathrm{LOQ}$ & $<$ LOQ \\
\hline Orphenadrine & $<\mathrm{LOQ}$ & $<$ LOQ & $<$ LOQ & $<$ LOQ & $<\mathrm{LOQ}$ & $<$ LOQ & $<\mathrm{LOQ}$ & $<$ LOQ & $<$ LOQ & $<\mathrm{LOQ}$ & $<$ LOQ \\
\hline \multicolumn{12}{|c|}{ Anticonvulsants } \\
\hline Acetazolamide & $<\mathrm{LOQ}$ & $<\mathrm{LOQ}$ & $<\mathrm{LOQ}$ & $<\mathrm{LOQ}$ & $<\mathrm{LOQ}$ & $<$ LOQ & $<\mathrm{LOQ}$ & $<$ LOQ & $<\mathrm{LOQ}$ & $<\mathrm{LOQ}$ & $<$ LOQ \\
\hline Carbamazepine & 410 & 450 & 420 & 660 & 440 & 490 & 470 & 500 & 470 & 470 & 480 \\
\hline Lamotrigine & 240 & $<L O Q$ & $<L O Q$ & 240 & $<\mathrm{LOQ}$ & $<\mathrm{LOQ}$ & $<\mathrm{LOQ}$ & $<L O Q$ & $<\mathrm{LOQ}$ & $<L O Q$ & $<$ LOQ \\
\hline Phenytoin & $<\mathrm{LOQ}$ & $<\mathrm{LOQ}$ & $<$ LOQ & $<\mathrm{LOQ}$ & $<\mathrm{LOQ}$ & $<\mathrm{LOQ}$ & $<\mathrm{LOQ}$ & $<$ LOQ & $<$ LOQ & $<$ LOQ & $<$ LOQ \\
\hline \multicolumn{12}{|c|}{ Antidiabetics } \\
\hline Glibenclamide & $<\mathrm{LOQ}$ & $<\mathrm{LOQ}$ & $<\mathrm{LOQ}$ & $<\mathrm{LOQ}$ & $<\mathrm{LOQ}$ & $<\mathrm{LOQ}$ & $<\mathrm{LOQ}$ & $<$ LOQ & $<\mathrm{LOQ}$ & $<\mathrm{LOQ}$ & $<$ LOQ \\
\hline Gliclazide & $<\mathrm{LOQ}$ & $<\mathrm{LOQ}$ & $<$ LOQ & $<$ LOQ & $<\mathrm{LOQ}$ & 46 & 38 & 48 & 42 & 46 & 46 \\
\hline \multicolumn{12}{|c|}{ Antidotes } \\
\hline Naloxone & $<\mathrm{LOQ}$ & $<$ LOQ & $<$ LOQ & $<\mathrm{LOQ}$ & $<\mathrm{LOQ}$ & $<\mathrm{LOQ}$ & $<\mathrm{LOQ}$ & $<\mathrm{LOQ}$ & $<\mathrm{LOQ}$ & $<$ LOQ & $<\mathrm{LOQ}$ \\
\hline \multicolumn{12}{|c|}{ Antihistamines } \\
\hline Antazoline & $<\mathrm{LOQ}$ & $<\mathrm{LOQ}$ & $<$ LOQ & $<$ LOQ & $<\mathrm{LOQ}$ & $<\mathrm{LOQ}$ & $<\mathrm{LOQ}$ & $<$ LOQ & $<\mathrm{LOQ}$ & $<$ LOQ & $<$ LOQ \\
\hline Cetirizine & $<\mathrm{LOQ}$ & $<$ LOQ & $<\mathrm{LOQ}$ & $<\mathrm{LOQ}$ & $<\mathrm{LOQ}$ & $<\mathrm{LOQ}$ & $<\mathrm{LOQ}$ & $<\mathrm{LOQ}$ & $<\mathrm{LOQ}$ & $<\mathrm{LOQ}$ & $<$ LOQ \\
\hline Chlorpheniramine & $<\mathrm{LOQ}$ & $<\mathrm{LOQ}$ & $<\mathrm{LOQ}$ & $<$ LOQ & $<\mathrm{LOQ}$ & $<\mathrm{LOQ}$ & $<\mathrm{LOQ}$ & $<\mathrm{LOQ}$ & $<\mathrm{LOQ}$ & $<\mathrm{LOQ}$ & $<$ LOQ \\
\hline Cimetidine & $<\mathrm{LOQ}$ & $<\mathrm{LOQ}$ & $<\mathrm{LOQ}$ & $<\mathrm{LOQ}$ & $<\mathrm{LOQ}$ & $<\mathrm{LOQ}$ & $<\mathrm{LOQ}$ & $<\mathrm{LOQ}$ & $<\mathrm{LOQ}$ & $<\mathrm{LOQ}$ & $<\mathrm{LOQ}$ \\
\hline Promethazine & $<\mathrm{LOQ}$ & $<\mathrm{LOQ}$ & $<\mathrm{LOQ}$ & $<\mathrm{LOQ}$ & $<\mathrm{LOQ}$ & $<\mathrm{LOQ}$ & $<\mathrm{LOQ}$ & $<$ LOQ & $<\mathrm{LOQ}$ & $<\mathrm{LOQ}$ & $<$ LOQ \\
\hline
\end{tabular}


Table A8 continued. Concentrations ( $\mathrm{ng} / \mathrm{L}$ ) of micropollutants in influent and effluent samples of the demonstration-scale decentralised wastewater treatment system in eThekwini

\begin{tabular}{|c|c|c|c|c|c|c|c|c|c|c|c|}
\hline \multirow[b]{3}{*}{ Compound } & \multicolumn{5}{|c|}{ Influent } & \multicolumn{6}{|c|}{ Effluent } \\
\hline & \multicolumn{2}{|c|}{ Day 1} & \multirow{2}{*}{$\begin{array}{c}\text { Day } 2 \\
07: 30\end{array}$} & \multicolumn{2}{|c|}{ Day 3} & \multicolumn{2}{|c|}{ Day 1} & \multicolumn{2}{|c|}{ Day 2} & \multicolumn{2}{|c|}{ Day 3} \\
\hline & 07:30 & $18: 00$ & & 07:30 & $18: 00$ & $07: 30$ & $18: 00$ & 07:30 & $18: 00$ & 07:30 & $18: 00$ \\
\hline \multicolumn{12}{|c|}{ Antihypertensives } \\
\hline Atenolol & $<\mathrm{LOQ}$ & $<\mathrm{LOQ}$ & $<\mathrm{LOQ}$ & $<\mathrm{LOQ}$ & $<\mathrm{LOQ}$ & 580 & $<\mathrm{LOQ}$ & $<\mathrm{LOQ}$ & $<\mathrm{LOQ}$ & $<\mathrm{LOQ}$ & $<\mathrm{LOQ}$ \\
\hline Bezafibrate & $<\mathrm{LOQ}$ & $<\mathrm{LOQ}$ & $<\mathrm{LOQ}$ & $<\mathrm{LOQ}$ & $<\mathrm{LOQ}$ & $<\mathrm{LOQ}$ & $<\mathrm{LOQ}$ & $<\mathrm{LOQ}$ & $<$ LOQ & $<$ LOQ & $<\mathrm{LOQ}$ \\
\hline Enalapril & 8300 & 6500 & 6300 & 9200 & 7800 & 8800 & 8400 & 8100 & 8100 & 7000 & 8100 \\
\hline Nifedipine & $<\mathrm{LOQ}$ & $<\mathrm{LOQ}$ & $<\mathrm{LOQ}$ & $<\mathrm{LOQ}$ & $<\mathrm{LOQ}$ & $<\mathrm{LOQ}$ & $<\mathrm{LOQ}$ & $<\mathrm{LOQ}$ & $<\mathrm{LOQ}$ & $<\mathrm{LOQ}$ & $<\mathrm{LOQ}$ \\
\hline \multicolumn{12}{|c|}{ Antimycotics } \\
\hline Clotrimazole & $<\mathrm{LOQ}$ & $<\mathrm{LOQ}$ & $<\mathrm{LOQ}$ & $<\mathrm{LOQ}$ & $<\mathrm{LOQ}$ & $<\mathrm{LOQ}$ & $<\mathrm{LOQ}$ & $<\mathrm{LOQ}$ & $<\mathrm{LOQ}$ & $<\mathrm{LOQ}$ & $<\mathrm{LOQ}$ \\
\hline Fluconazole & 1100 & 670 & 810 & 570 & 510 & 1900 & 1900 & 1900 & 1800 & 1800 & 1700 \\
\hline \multicolumn{12}{|c|}{ Antiparasitics } \\
\hline Albendazole & $<\mathrm{LOQ}$ & $<\mathrm{LOQ}$ & $<\mathrm{LOQ}$ & $<\mathrm{LOQ}$ & $<\mathrm{LOQ}$ & $<\mathrm{LOQ}$ & $<\mathrm{LOQ}$ & $<\mathrm{LOQ}$ & $<$ LOQ & $<\mathrm{LOQ}$ & $<\mathrm{LOQ}$ \\
\hline \multicolumn{12}{|c|}{ Antiretrovirals } \\
\hline Abacavir & 290 & 100 & 69 & 29 & 21 & 500 & 550 & 570 & 540 & 550 & 550 \\
\hline Atazanavir & 3400 & 3100 & 2400 & 3500 & 2900 & 2700 & 2900 & 3500 & 3200 & 2600 & 3300 \\
\hline Darunavir & 16000 & 10000 & 14000 & 17000 & 12000 & 9200 & 10000 & 9100 & 9700 & 12000 & 10000 \\
\hline Etravirine & $<\mathrm{LOQ}$ & $<\mathrm{LOQ}$ & $<\mathrm{LOQ}$ & $<\mathrm{LOQ}$ & $<\mathrm{LOQ}$ & $<\mathrm{LOQ}$ & $<\mathrm{LOQ}$ & $<\mathrm{LOQ}$ & $<\mathrm{LOQ}$ & $<\mathrm{LOQ}$ & $<\mathrm{LOQ}$ \\
\hline Lamivudine & 85000 & 85000 & 65000 & 47000 & 86000 & 94000 & 120000 & 140000 & 130000 & 130000 & 150000 \\
\hline Nevirapine & 340 & 320 & 310 & 420 & 370 & 280 & 310 & 330 & 360 & 390 & 440 \\
\hline Raltegravir & 4000 & 2200 & 2400 & 6300 & 5800 & 3300 & 3300 & 3300 & 4100 & 3400 & 3800 \\
\hline Saquinavir & $<\mathrm{LOQ}$ & $<\mathrm{LOQ}$ & $<\mathrm{LOQ}$ & $<$ LOQ & $<\mathrm{LOQ}$ & $<\mathrm{LOQ}$ & $<\mathrm{LOQ}$ & $<\mathrm{LOQ}$ & $<$ LOQ & $<\mathrm{LOQ}$ & $<\mathrm{LOQ}$ \\
\hline \multicolumn{12}{|c|}{ Antivirals } \\
\hline Aciclovir & 2000 & 4700 & 2700 & 1700 & 3800 & 2400 & 2600 & 2200 & 1400 & 1600 & 1300 \\
\hline Famciclovir & $<\mathrm{LOQ}$ & $<\mathrm{LOQ}$ & $<\mathrm{LOQ}$ & $<\mathrm{LOQ}$ & $<\mathrm{LOQ}$ & $<\mathrm{LOQ}$ & $<\mathrm{LOQ}$ & $<\mathrm{LOQ}$ & $<\mathrm{LOQ}$ & $<\mathrm{LOQ}$ & $<\mathrm{LOQ}$ \\
\hline \multicolumn{12}{|c|}{ Decongestants } \\
\hline Oxymetazoline & $<\mathrm{LOQ}$ & $<$ LOQ & $<$ LOQ & $<$ LOQ & $<\mathrm{LOQ}$ & $<\mathrm{LOQ}$ & $<\mathrm{LOQ}$ & $<\mathrm{LOQ}$ & $<\mathrm{LOQ}$ & $<\mathrm{LOQ}$ & $<\mathrm{LOQ}$ \\
\hline \multicolumn{12}{|c|}{ Herbicides/pesticides } \\
\hline Atrazine & $<\mathrm{LOQ}$ & $<\mathrm{LOQ}$ & $<\mathrm{LOQ}$ & $<\mathrm{LOQ}$ & $<\mathrm{LOQ}$ & $<\mathrm{LOQ}$ & $<\mathrm{LOQ}$ & $<\mathrm{LOQ}$ & $<$ LOQ & $<\mathrm{LOQ}$ & $<\mathrm{LOQ}$ \\
\hline Tebuthiuron & 100 & 110 & 86 & 66 & 120 & 90 & 100 & 130 & 120 & 110 & 100 \\
\hline Terbuthylazine & $<\mathrm{LOQ}$ & 56 & 25 & 41 & 43 & $<\mathrm{LOQ}$ & 43 & 62 & 59 & 46 & 53 \\
\hline \multicolumn{12}{|c|}{ Hormonal contraceptives } \\
\hline Levonorgestrel & $<\mathrm{LOQ}$ & $<\mathrm{LOQ}$ & $<\mathrm{LOQ}$ & $<\mathrm{LOQ}$ & $<\mathrm{LOQ}$ & $<\mathrm{LOQ}$ & $<$ LOQ & $<\mathrm{LOQ}$ & $<$ LOQ & $<\mathrm{LOQ}$ & $<\mathrm{LOQ}$ \\
\hline Medroxyprogesterone & $<\mathrm{LOQ}$ & $<\mathrm{LOQ}$ & $<$ LOQ & $<\mathrm{LOQ}$ & $<\mathrm{LOQ}$ & $<\mathrm{LOQ}$ & $<\mathrm{LOQ}$ & $<\mathrm{LOQ}$ & $<\mathrm{LOQ}$ & $<\mathrm{LOQ}$ & $<\mathrm{LOQ}$ \\
\hline Norgestrel & $<\mathrm{LOQ}$ & $<\mathrm{LOQ}$ & $<\mathrm{LOQ}$ & $<\mathrm{LOQ}$ & $<\mathrm{LOQ}$ & $<\mathrm{LOQ}$ & $<\mathrm{LOQ}$ & $<$ LOQ & $<$ LOQ & $<\mathrm{LOQ}$ & $<\mathrm{LOQ}$ \\
\hline Progesterone & $<\mathrm{LOQ}$ & $<\mathrm{LOQ}$ & $<\mathrm{LOQ}$ & $<$ LOQ & $<\mathrm{LOQ}$ & $<\mathrm{LOQ}$ & $<\mathrm{LOQ}$ & $<\mathrm{LOQ}$ & $<\mathrm{LOQ}$ & $<\mathrm{LOQ}$ & $<\mathrm{LOQ}$ \\
\hline \multicolumn{12}{|c|}{ Psycholeptics/antidepressants } \\
\hline Amitriptyline & $<\mathrm{LOQ}$ & $<\mathrm{LOQ}$ & $<\mathrm{LOQ}$ & $<\mathrm{LOQ}$ & $<\mathrm{LOQ}$ & $<\mathrm{LOQ}$ & $<\mathrm{LOQ}$ & $<\mathrm{LOQ}$ & $<\mathrm{LOQ}$ & $<\mathrm{LOQ}$ & $<\mathrm{LOQ}$ \\
\hline Clozapine & $<\mathrm{LOQ}$ & $<\mathrm{LOQ}$ & $<\mathrm{LOQ}$ & $<$ LOQ & $<\mathrm{LOQ}$ & $<\mathrm{LOQ}$ & $<\mathrm{LOQ}$ & $<\mathrm{LOQ}$ & $<\mathrm{LOQ}$ & $<\mathrm{LOQ}$ & $<\mathrm{LOQ}$ \\
\hline Diazepam & $<\mathrm{LOQ}$ & $<\mathrm{LOQ}$ & $<\mathrm{LOQ}$ & $<$ LOQ & $<\mathrm{LOQ}$ & $<\mathrm{LOQ}$ & $<\mathrm{LOQ}$ & $<\mathrm{LOQ}$ & $<\mathrm{LOQ}$ & $<\mathrm{LOQ}$ & $<\mathrm{LOQ}$ \\
\hline Fluoxetine & $<\mathrm{LOQ}$ & $<\mathrm{LOQ}$ & $<\mathrm{LOQ}$ & $<\mathrm{LOQ}$ & $<\mathrm{LOQ}$ & $<\mathrm{LOQ}$ & $<\mathrm{LOQ}$ & $<\mathrm{LOQ}$ & $<\mathrm{LOQ}$ & $<\mathrm{LOQ}$ & $<\mathrm{LOQ}$ \\
\hline Haloperidol & $<\mathrm{LOQ}$ & $<\mathrm{LOQ}$ & $<\mathrm{LOQ}$ & $<\mathrm{LOQ}$ & $<\mathrm{LOQ}$ & $<\mathrm{LOQ}$ & $<\mathrm{LOQ}$ & $<\mathrm{LOQ}$ & $<\mathrm{LOQ}$ & $<\mathrm{LOQ}$ & $<\mathrm{LOQ}$ \\
\hline Lorazepam & $<\mathrm{LOQ}$ & $<\mathrm{LOQ}$ & $<\mathrm{LOQ}$ & $<\mathrm{LOQ}$ & $<\mathrm{LOQ}$ & $<\mathrm{LOQ}$ & $<\mathrm{LOQ}$ & $<\mathrm{LOQ}$ & $<\mathrm{LOQ}$ & $<\mathrm{LOQ}$ & $<\mathrm{LOQ}$ \\
\hline Oxazepam & $<\mathrm{LOQ}$ & $<\mathrm{LOQ}$ & $<\mathrm{LOQ}$ & $<\mathrm{LOQ}$ & $<\mathrm{LOQ}$ & $<\mathrm{LOQ}$ & $<\mathrm{LOQ}$ & $<\mathrm{LOQ}$ & $<\mathrm{LOQ}$ & $<\mathrm{LOQ}$ & $<\mathrm{LOQ}$ \\
\hline \multicolumn{12}{|c|}{ Stimulants } \\
\hline Caffeine & 22000 & 23000 & 16000 & 19000 & 29000 & 9000 & 9200 & 7900 & 6900 & 6100 & 5800 \\
\hline
\end{tabular}


Table A9. Removal efficiencies (\%) of Newlands Mashu decentralised wastewater treatment system (NM DEWATS); and other decentralised wastewater treatment systems (DEWATS) and conventional wastewater treatment plants (WWTP) reported in literature

\begin{tabular}{|c|c|c|c|c|}
\hline Compound & NM DEWATS & DEWATS & WWTP & Reference \\
\hline & \multicolumn{4}{|l|}{ this publication } \\
\hline \multicolumn{5}{|c|}{ Analgesics/anti-inflammatory drugs } \\
\hline Diclofenac & 11 & $82^{1}$ & 24 & Schaider et al., 2017 \\
\hline Paracetamol & 97 & $99.8^{1}$ & 99.8 & Schaider et al., 2017 \\
\hline Tramadol & -21 & $53^{2}$ & 50 & Gomes et al., 2008; Vymazal et al., 2017 \\
\hline \multicolumn{5}{|c|}{ Antibiotics } \\
\hline Ciprofloxacin & -17 & - & 69 & Margot et al., 2015 \\
\hline Clindamycin & 3 & - & $<0$ & Gurke et al., 2015 \\
\hline Levofloxacin & 11 & - & 75 & Golovko et al., 2014 \\
\hline Sulfamethoxazole & 79 & $40^{1}$ & 47 & Schaider et al., 2017 \\
\hline Trimethoprim & 79 & $60^{1}$ & 70 & Schaider et al., 2017 \\
\hline \multicolumn{5}{|c|}{ Anticonvulsants } \\
\hline Carbamazepine & 0 & $8^{1}$ & 8.6 & Schaider et al., 2017 \\
\hline \multicolumn{5}{|c|}{ Antihypertensives } \\
\hline Enalapril & -6 & - & $>60.7$ & Gurke et al. 2015 \\
\hline \multicolumn{5}{|c|}{ Antimycotics } \\
\hline Fluconazole & -150 & - & 15 & Margot et al., 2015 \\
\hline \multicolumn{5}{|c|}{ Antiretrovirals } \\
\hline Abacavir & -430 & $62-100^{3}$ & $>99$ & McCurry et al., 2014; Prasse et al., 2010 \\
\hline Atazanavir & 1 & - & - & \\
\hline Darunavir & 28 & - & - & \\
\hline Lamivudine & -73 & $90-100^{3}$ & $24-59,>76$ & K'Oreje et al., 2016; McCurry et al., 2014; Prasse et al., 2010 \\
\hline Nevirapine & 0 & - & $11-39,0$ & K'Oreje et al., 2016; Prasse et al., 2010 \\
\hline Raltegravir & 15 & - & - & \\
\hline \multicolumn{5}{|c|}{ Antivirals } \\
\hline Aciclovir & 36 & $94-96^{3}$ & 98 & McCurry et al., 2014; Prasse et al., 2010 \\
\hline \multicolumn{5}{|c|}{ Herbicides/pesticides } \\
\hline Tebuthiuron & -12 & - & - & \\
\hline Terbuthylazine & -28 & - & 24 & Margot et al., 2015 \\
\hline \multicolumn{5}{|c|}{ Stimulants } \\
\hline Caffeine & 66 & $99.63^{1}$ & 80 & Schaider et al., 2017 \\
\hline
\end{tabular}

${ }^{1}$ septic tank, drainfield; ${ }^{2}$ constructed wetland; ${ }^{3}$ membrane bioreactor 
Table A10. Average removal efficiencies $(\%)(n=3)$ of micropollutants from South African wastewater using biochars produced from olive residues, tomato residues, rice husk, and Raphia farinifera

\begin{tabular}{|c|c|c|c|c|}
\hline & Olive & Tomato & Rice husk & Raphia farinifera \\
\hline \multicolumn{5}{|c|}{ Analgesics/anti-inflammatory drugs } \\
\hline Diclofenac & 31 & 9.7 & 5 & 23 \\
\hline Paracetamol & 51 & 35 & 26 & 41 \\
\hline Tramadol & 79 & 68 & 73 & 43 \\
\hline \multicolumn{5}{|c|}{ Antibiotics } \\
\hline Ciprofloxacin & 100 & 100 & 100 & 100 \\
\hline Clindamycin & 70 & 40 & 34 & -73 \\
\hline Levofloxacin & 100 & 100 & 100 & 100 \\
\hline Sulfamethoxazole & 63 & 100 & 53 & 63 \\
\hline Trimethoprim & 100 & 93 & 92 & 83 \\
\hline \multicolumn{5}{|c|}{ Anticonvulsants } \\
\hline Carbamazepine & 61 & 1.3 & 38 & 50 \\
\hline Lamotrigine & 100 & 19 & 100 & 100 \\
\hline \multicolumn{5}{|c|}{ Antidiabetics } \\
\hline Gliclazide & 45 & 6.1 & -11 & 52 \\
\hline \multicolumn{5}{|c|}{ Antihypertensives } \\
\hline Enalapril & 20 & -2.9 & -13 & 20 \\
\hline \multicolumn{5}{|c|}{ Antimycotics } \\
\hline Fluconazole & 22 & 6.2 & 5.6 & 29 \\
\hline \multicolumn{5}{|c|}{ Antiretrovirals } \\
\hline Abacavir & 55 & 37 & 44 & 33 \\
\hline Atazanavir & 76 & 38 & 63 & 60 \\
\hline Darunavir & 75 & 51 & 57 & 48 \\
\hline Lamivudine & 64 & 57 & -21 & 74 \\
\hline Nevirapine & 43 & 19 & 27 & 40 \\
\hline Raltegravir & 63 & 76 & 61 & 75 \\
\hline \multicolumn{5}{|c|}{ Antivirals } \\
\hline Aciclovir & -31 & 40 & 18 & 36 \\
\hline \multicolumn{5}{|c|}{ Herbicides/pesticides } \\
\hline Tebuthiuron & 75 & 36 & 36 & 56 \\
\hline Terbuthylazine & 100 & 100 & 100 & 100 \\
\hline \multicolumn{5}{|c|}{ Stimulants } \\
\hline Caffeine & 53 & 37 & 34 & 58 \\
\hline
\end{tabular}

